\title{
DMF as CO Surrogate in Carbonylation Reactions: Principles and Application to the Synthesis of Heterocycles
}

\author{
Biswajit Panda ${ }^{1, *}$ and Gianluigi Albano ${ }^{2, *}$ (D) \\ 1 Department of Chemistry, City College, 102/1 Raja Rammohan Sarani, Kolkata 700009, India \\ 2 Dipartimento di Chimica, Università degli Studi di Bari "Aldo Moro", Via Edoardo Orabona 4, \\ 70126 Bari, Italy \\ * Correspondence: biswajitchem@gmail.com (B.P.); gianluigi.albano@uniba.it (G.A.)
}

Citation: Panda, B.; Albano, G. DMF as CO Surrogate in Carbonylation Reactions: Principles and Application to the Synthesis of Heterocycles. Catalysts 2021, 11, 1531. https:// doi.org/10.3390/catal11121531

Academic Editor: Min Kim

Received: 20 November 2021 Accepted: 8 December 2021 Published: 16 December 2021

Publisher's Note: MDPI stays neutral with regard to jurisdictional claims in published maps and institutional affiliations.

Copyright: (c) 2021 by the authors. Licensee MDPI, Basel, Switzerland. This article is an open access article distributed under the terms and conditions of the Creative Commons Attribution (CC BY) license (https:// creativecommons.org/licenses/by/ $4.0 /)$.

\begin{abstract}
Transition metal-catalyzed carbonylation reactions have emerged as one of the most relevant synthetic approaches for the preparation of carbonyl-containing molecules. The most commonly used protocol for the insertion of a carbonyl moiety is the use of carbon monoxide (CO) but, due to its toxic and explosive nature, this process is not suitable at an industrial scale. More recently, the chemistry of CO surrogates has received large attention as a way to use less expensive and more environmentally friendly methods. Among the various CO surrogates, $N, N-$ dimethylformamide (DMF) has been paid greater attention due to its low cost and easy availability. This mini-review gives appealing insights into the application of DMF as a CO surrogate in metalcatalyzed carbonylations; in particular, in the first part we will give a general state of the art of these reactions for the preparation of carbonyl-containing molecules; then, we will take into account all the various synthetic approaches for the metal-catalyzed carbonylative synthesis of heterocycles using DMF as a CO surrogate. Each protocol has been discussed critically in order to screen the best synthetic method and to offer perspective on trends and future directions in this field.
\end{abstract}

Keywords: carbonylation; catalytic processes; CO surrogates; DMF; heterocycles; synthetic methods

\section{Introduction}

The carbonyl functional group is very common in both natural and synthetic organic compounds: on the one hand, its chemical reactivity often plays a crucial role in several biological processes [1]; on the other, its ability as a hydrogen-bonding acceptor allows for appealing applications in supramolecular chemistry [2,3]. In light of these considerations, the development of efficient synthetic methods for the preparation of carbonyl-containing compounds has long attracted the attention of organic chemists all over the world.

One of the most common approach for introducing carbonyl moieties is represented by transition metal-catalyzed carbonylation, i.e., reactions involving carbon monoxide (CO) as a source of the carbonyl group. From the first pioneering study on Pd-catalyzed carbonylation reactions, reported by Heck et al. in 1974 [4], several transition metal species (in particular palladium, rhodium, iridium, nickel, ruthenium, iron and cobalt) have been successfully applied as catalysts in the synthesis of countless carbonyl-functionalized molecules by carbonylation reactions involving $\mathrm{CO}$ as a $\mathrm{C}_{1}$-carbon source $[5,6]$.

Although some examples of carbonylative protocols have even been applied on industrial scale (e.g., in the industrial synthesis of acetic acid by rhodium-catalyzed [7] or iridium-catalyzed [8] carbonylation of $\mathrm{MeOH}$ ), one of the major drawbacks of these reactions is the difficulty in the handling, storage and transport of carbon monoxide, a flammable and toxic greenhouse gas. Therefore, the development of transition metalcatalyzed carbonylation protocols involving the use of $\mathrm{CO}$ surrogates, rather than $\mathrm{CO}$ gas, is a crucial aspect to address this challenge in the context of a more sustainable chemistry.

The CO surrogates are species able of producing in-situ carbon monoxide, as a result of suitable chemical reactions; in this way, toxic $\mathrm{CO}$ is generated and directly consumed 
in a closed reaction flask, thus avoiding the requirement of high-pressure equipment and minimizing its exposure to operators [9-11]. Thanks to these advantages, the application of $\mathrm{CO}$ surrogates in carbonylation reactions has known significant advances in the last years, becoming an attractive area of research for synthetic organic chemists. The most common CO surrogates are metal carbonyl complexes [12], formic acid [13], formates [14] and formaldehyde [15], although studies involving the use of oxalic acid [16], carbon dioxide [17], chloroform [18] and so on have been also reported.

In this context, $N, N$-dimethylformamide (DMF) has recently found space as an appealing $\mathrm{CO}$ surrogate in transition metal-catalyzed carbonylation reactions. Compared with other CO surrogates-such as metal carbonyl complexes, whose use in stoichiometric amounts is problematic on a large scale as it may cause serious environmental pollution, or formaldehyde, whose manipulation is far from trivial-DMF is a cheap and easily accessible compound, typically used as a polar aprotic solvent in several organic reactions, easy to manipulate and also compatible for scale-up (Scheme 1a).

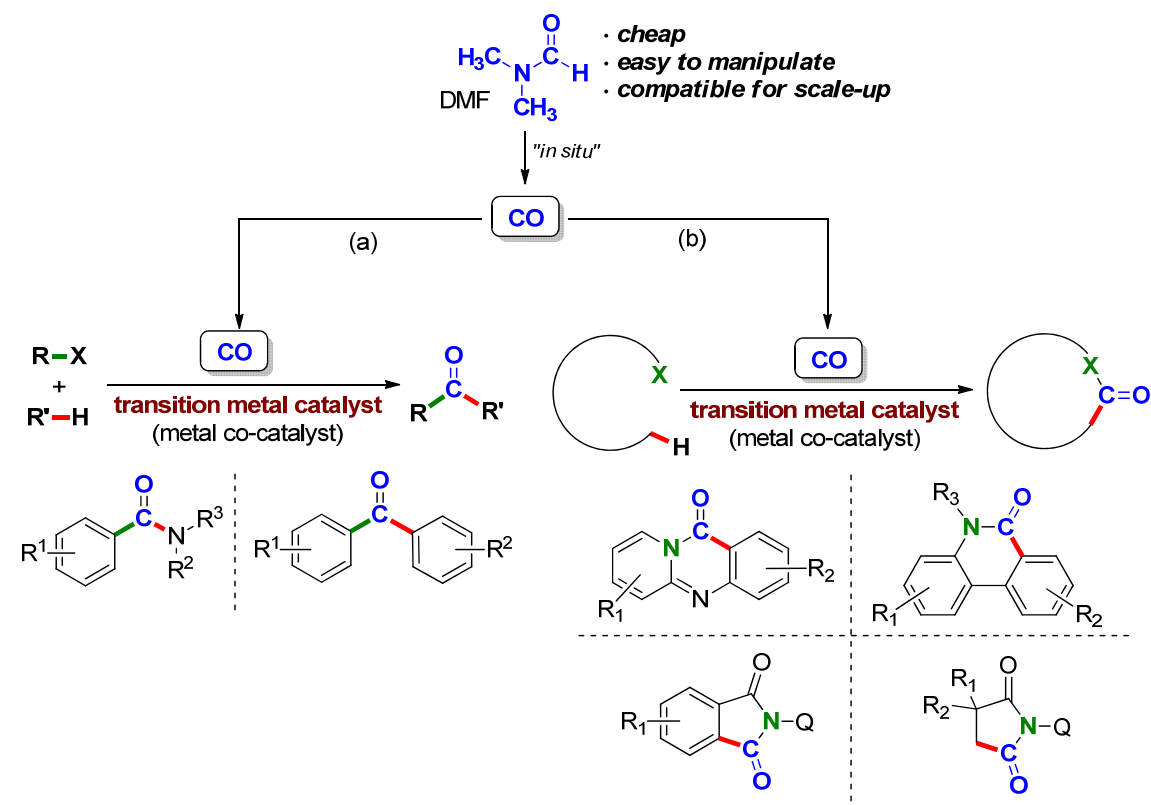

Scheme 1. Transition metal-catalyzed carbonylation reactions involving DMF as CO surrogate: (a) general scheme for the synthesis of carbonyl-containing molecules; (b) application to the synthesis of heterocycles.

Transition metal-catalyzed carbonylation reactions have acquired a prominent role in the field of the organic chemistry also for the synthesis of a multitude of useful carbonylcontaining heterocycles; in this context, we recently reported the application of cyclocarbonylative Sonogashira [19-22] and silylcarbocyclization reactions [23-25] for the synthesis of several classes of oxygen- and nitrogen-containing heterocycles. However, despite many advancements have been made in order to improve the feasibility and sustainability of these processes, the use of carbon monoxide represents a vexing problem which limits the widespread use of cyclocarbonylative reactions to some degree. The application of $\mathrm{CO}$ surrogates allowed to overcome this problem: in the last ten years, various carbonylative synthesis of heterocycles involving diverse CO surrogates have been successfully developed [26]. Thanks to the above-mentioned advantages, it should not be surprising that DMF is recently also finding success for the synthesis of heterocycles (Scheme 1b).

The application of DMF as a CO surrogate in metal-catalyzed carbonylation reactions has been partially described, to date, only as part of more general reviews, focusing on the use of DMF as a multipurpose building block in several classes of reactions [27] in carbonylation protocols involving diverse $\mathrm{CO}$ surrogates [6] or in the carbonylative synthesis of heterocycles based on several classes of CO surrogates [26]. However, in 
all these reports we found a pure description of the experimental conditions without any critical discussion of both advantages and disadvantages. Therefore, a complete overview only focused on transition metal-catalyzed carbonylations involving DMF as a $\mathrm{CO}$ surrogate, giving not only a general state of the art of these reactions for the preparation of carbonyl-containing molecules but also an in-depth discussion of their application in the synthesis of heterocycles, is still missing. In this mini-review we shall try to achieve this purpose. In the first section we will give some general considerations on transition metal-catalyzed carbonylation reactions with DMF as a source of $\mathrm{CO}$ for the preparation of acyclic carbonyl-containing molecules; in the second section we will consider the more specific cyclocarbonylative protocols for the preparation of heterocycles. In both sections we will give special emphasis to the adopted catalytic systems, the reaction mechanisms and the substrates scope. Although the examples described in the literature could appear still quite limited, we believe that a concise and critical overview is very useful at this stage, in order to suggest perspective on developments, trends and future directions in the context of metal-catalyzed carbonylative protocols, and more in detail for the synthesis of heterocycles.

\section{Transition Metal-Catalyzed Carbonylation Reactions Involving DMF as a CO Surrogate}

\subsection{Palladium-Catalyzed Carbonylation Involving DMF as a CO Surrogate}

The use of DMF as a formal source of carbon monoxide in carbonylation reactions for the synthesis of carbonyl-containing molecules has been reported, in most cases, in the presence of a palladium catalyst. The first study in this context was reported in 2002 by Hallberg, Alterman et al., who described the aminocarbonylation of aryl bromides with amines, in the presence of DMF as a CO surrogate [28]. Reactions were performed by treatment of aryl bromides $\mathbf{1}$ with 4.0 equiv. of a primary or secondary amine $\mathbf{2}$, in the presence of $\mathrm{Pd}(\mathrm{OAc})_{2} / \mathrm{dppf}(5 \mathrm{~mol} \%)$ as the catalytic system, imidazole (1.0 equiv.) as an additive and potassium $t$-butoxide (1.5 equiv.) as a base, under microwaves irradiation in DMF, acting as both solvent and reagent (Scheme 2). The substrate scope of this first work was quite limited: On one hand, the protocol was only applied to aryl bromides 1 bearing electron-rich groups (Me, $\mathrm{OMe}$ ) in the ortho- or para-position, while it failed with electron-deficient substrates; on the other, only benzyl amine, aniline and morpholine were tested as the other coupling partner. However, the aminocarbonylation products 3 were obtained in good yields (76-94\%) after very short reaction times (15-20 min), mainly thanks to the use of microwaves as a highly efficient energy source.

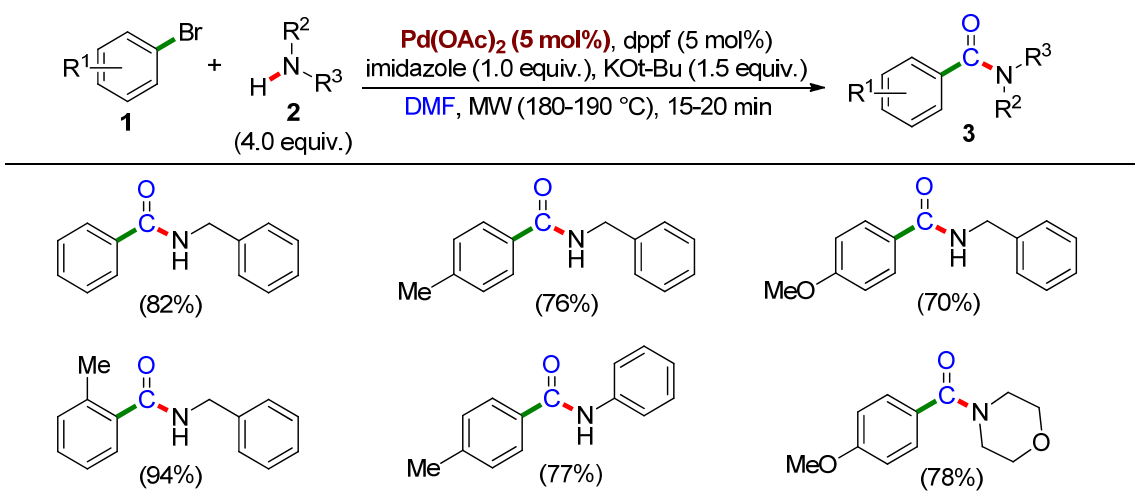

Scheme 2. Pd-catalyzed aminocarbonylation of aryl bromides $\mathbf{1}$ with amines $\mathbf{2}$, in the presence of DMF as a CO surrogate, reported in 2002 by Hallberg, Alterman et al. [28]. For each carbonylated product 3, yield after column chromatography purification was reported in brackets.

The reaction mechanism proposed by the authors (Scheme 3) clearly highlights the role played by the $\mathrm{Pd}(\mathrm{OAc})_{2} / \mathrm{dppf}$ catalytic system, as well as that of both $t$-OBuK and imidazole as, respectively, base and additive. Since it is well established that DMF, under 
heating, may decompose to yield carbon monoxide and dimethylamine in the presence of base [29], potassium $t$-butoxide could promote this transformation under the MW heating. The resulting CO may then enter into the palladium catalytic cycle: after the oxidative addition step of a palladium(0) species to the aryl bromide 1, the resulting arylpalladium(II) complex 4 can coordinate the in-situ-generated $\mathrm{CO}$, to give the corresponding aroylpalladium(II) intermediate 5 . At this point, imidazole can give a nucleophilic substitution to the acyl moiety of intermediate $\mathbf{5}$, affording a hydropalladium(II) complex and aroylimidazole 6. The subsequent nucleophilic substitution of amine $\mathbf{2}$ to the aroylimidazole $\mathbf{6}$ afforded the final product 3 , while a potassium $t$-butoxide-assisted reductive elimination of the hydropalladium(II) complex gave the $\operatorname{Pd}(0)$, which started a new cycle. From this mechanism, it is clear that the formation of dimethylamine as a by-product of DMF decomposition could represent an issue for the formation of the desired products 3 , as it could compete with the amine $\mathbf{2}$ in the nucleophilic substitution step to the aroylimidazole $\mathbf{6}$; in order to avoid this parasitic reaction, the amine 2 was used in large excess (4.0 equiv.) with respect to the aryl bromide 1 . Moreover, the use of dppf as a ligand rather than of a monodentate phosphine ligand was due to the fact that bidentate ligands are able to inhibit the formation of less-active palladium(II)-carbonyl complexes.

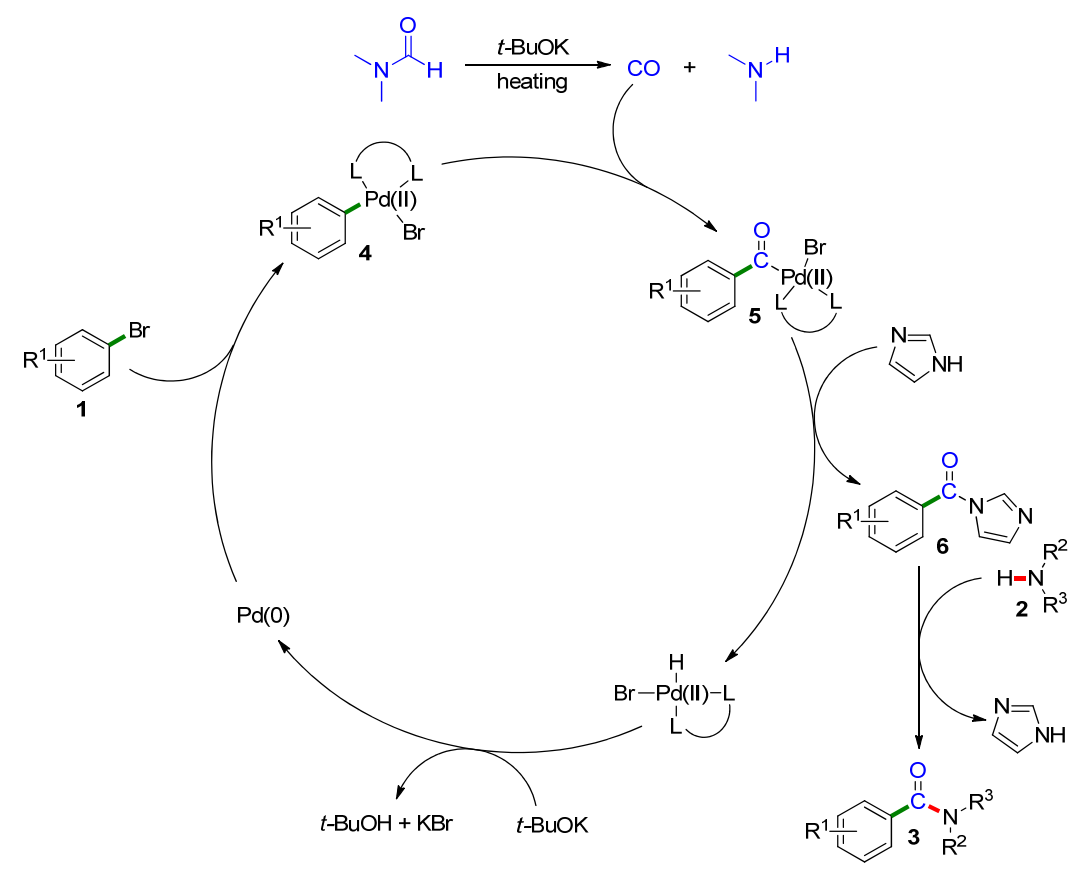

Scheme 3. Proposed reaction mechanism for the Pd-catalyzed aminocarbonylation of aryl bromides 1 with amines 2 using DMF as a CO surrogate, reported in 2002 by Hallberg, Alterman et al. [28].

In the same year, Hiyama and Nozaki reported, instead, a CO-free aminocarbonylation of aryl and alkenyl iodides 7, using DMF not as a simple source of CO but of the entire amide group [30]. In more detail, the reactions were carried out in the presence of $\operatorname{Pd}_{2}\left(\mathrm{dba}_{3}\right.$ $(2.5 \mathrm{~mol} \%)$ as the catalytic system under ligand-free conditions, in the presence of $\mathrm{POCl}_{3}$ (2.0 equiv.) as an additive and DMF as the usual solvent and reagent, at $120^{\circ} \mathrm{C}$ for $10-36 \mathrm{~h}$, affording the corresponding $\mathrm{N}, \mathrm{N}$-dimethylamide products 8 in high yields (Scheme 4). Compared to the work of Hallberg, Alterman et al., such protocol showed several advantages: first, working in the absence of any ligand, the total cost of the process was lower and also the purification of the coupling products was easier. Second, the substrate scope was broader; reactions worked very well on aryl iodides bearing both electron-donating and electron-withdrawing groups, while only one example was performed on alkenyl iodides. On the other hand, there are also some drawbacks: the use of iodides as coupling partners, which are more expensive than the corresponding bromides; the absence of MW irradiation, 
thus requiring high temperatures for long reaction times; the possibility of synthesizing only $\mathrm{N}, \mathrm{N}$-dimethylamides, due to the absence of other amines as coupling partners.

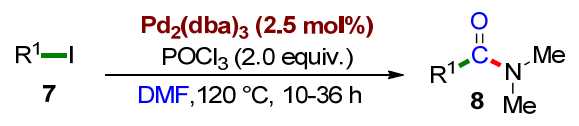

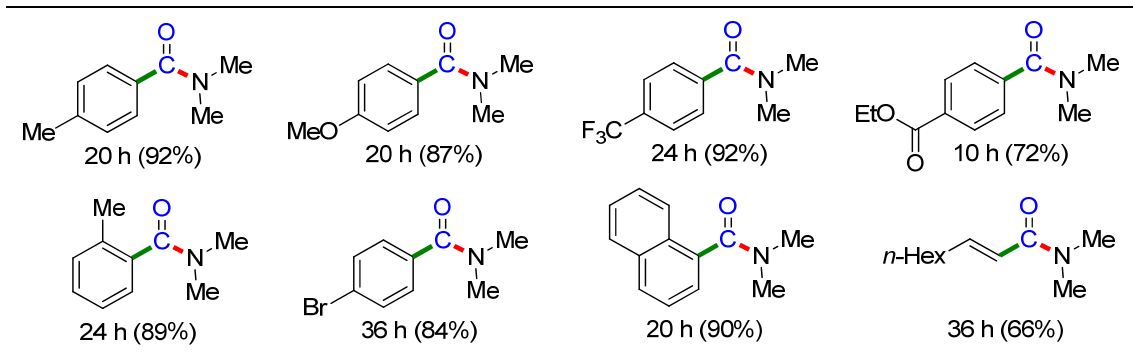

Scheme 4. Pd-catalyzed aminocarbonylation of aryl and alkenyl iodides 7 , in the presence of DMF as a source of $\mathrm{CO}$ and $\mathrm{N}, \mathrm{N}$-dimethylamino groups, reported in 2002 by Hiyama, Nozaki et al. [30]. For each carbonylated product 8 , reaction time and yield after column chromatography purification (in brackets) were reported.

Interestingly, the reaction mechanism proposed by the authors for this aminocarbonylative protocol (Scheme 5) was quite different from that of Hallberg, Alterman et al., although no studies were actually carried out in order to corroborate it. First of all, $\operatorname{Pd}(0)$ can give an oxidative addition to the organic iodide 7 , affording the corresponding organopalladium(II) 9; at the same time, DMF can give the corresponding iminium salt 10 by reaction with $\mathrm{POCl}_{3}$ (Vilsmeier reagent) [31]. Such mechanism then proceeded through a Heck-type path, with a carbopalladation of 9 to the $\mathrm{C}=\mathrm{N}$ double bond of iminium salt 10, affording the intermediate 11, followed by dehydropalladation to give a new organoiminium salt $\mathbf{1 2}$ and a hydropalladium(II) complex. Hydrolysis of $\mathbf{1 2}$ afforded the final $\mathrm{N}, \mathrm{N}$-dimethylamide product 8 , while the reductive elimination of hydropalladium(II) complex afforded the starting $\operatorname{Pd}(0)$ species.

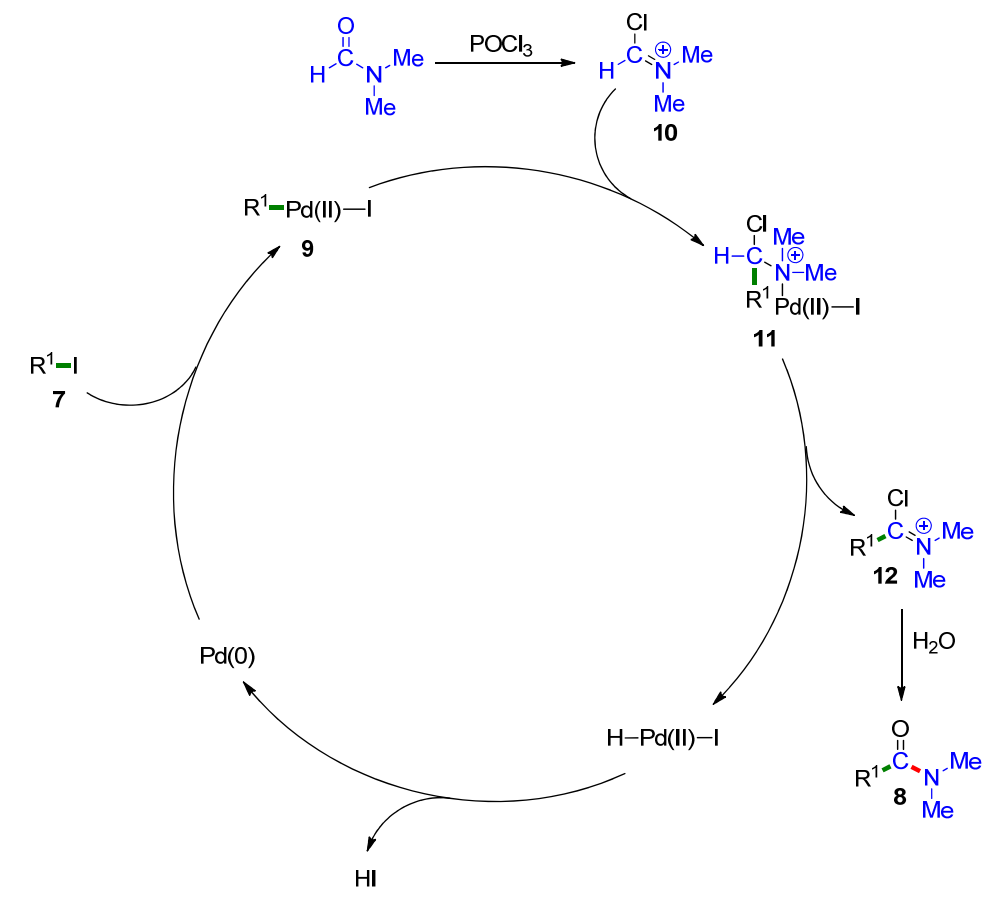

Scheme 5. Proposed reaction mechanism for the Pd-catalyzed aminocarbonylation of aryl and alkenyl iodides 7 , in the presence of DMF as a source of $\mathrm{CO}$ and $N, N$-dimethylamino groups, reported in 2002 by Hiyama, Nozaki et al. [30]. 
More recently, the palladium-catalyzed carbonylation involving DMF as a CO surrogate have been widely investigated by Bhanage et al. Their first study on this topic was reported in 2008: starting from the previous investigation of Hiyama and Nozaki, the aminocarbonylation of aryl iodides $\mathbf{1 3}$ with DMF, acting as the source of both $\mathrm{CO}$ and $\mathrm{N}, \mathrm{N}$-dimethylamino group, was performed here using commercial $\mathrm{Pd} / \mathrm{C}$ as catalyst [32]. Reactions were carried out with a Pd loading of $10 \mathrm{~mol} \%, 2.0$ equiv. of $\mathrm{POCl}_{3}$ as an additive, in DMF at $140{ }^{\circ} \mathrm{C}$ for $24 \mathrm{~h}$, affording the corresponding $\mathrm{N}, \mathrm{N}$-dimethylamide products 14 in $63-76 \%$ yields (Scheme 6 ). Therefore, the experimental conditions were very similar to the previous work of Hiyama and Nozaki, although a four times larger catalytic loading was used here $\left(2.5 \mathrm{~mol} \%\right.$ of $\mathrm{Pd}_{2}(\mathrm{dba})_{3}$ vs. $10 \mathrm{~mol} \%$ of $\left.\mathrm{Pd} / \mathrm{C}\right)$. One of the most critical points of this work was the determination of the true mechanism (heterogeneous vs. homogeneous) of the catalyst: ICP-AES analysis revealed that a significant amount of palladium species had leached into the solution, thus suggesting the possibility of a homogeneous reaction mechanism. If the possibility of thermal redeposition at $140^{\circ} \mathrm{C}$ at the end of the reaction allowed for a moderate catalyst reusability (up to three consecutive cycles), the problem of metal contamination of the coupling products (typically observed by using homogeneous metal catalysts) still remains unsolved. A further limitation of this protocol is related to the yields of $\mathrm{N}, \mathrm{N}$-dimethylamide products, which were generally lower if compared of those of the previous work of Hiyama and Nozaki (63-76\% of 14 vs. $72-92 \%$ of 8 ).

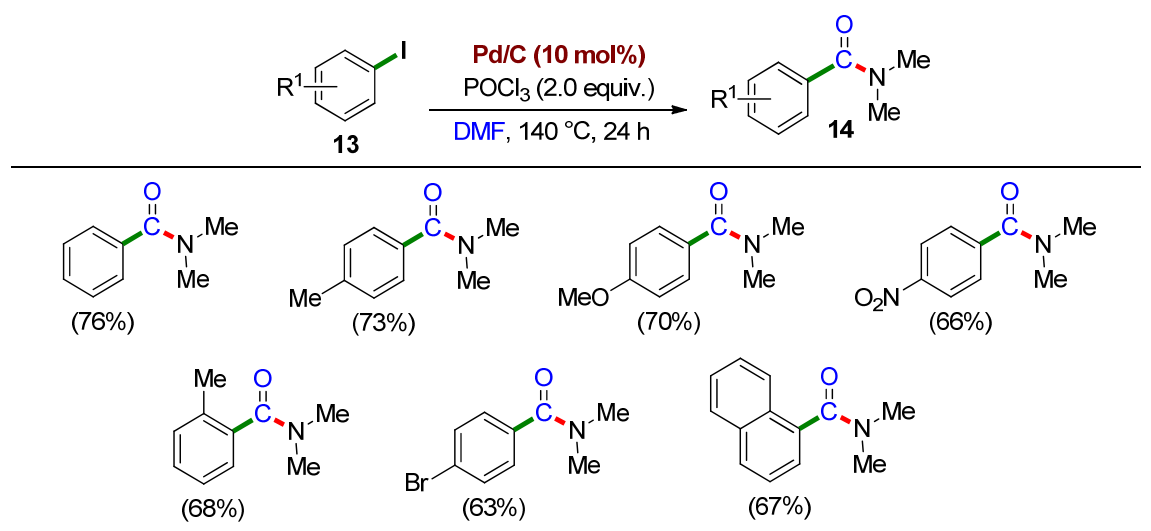

Scheme 6. Pd-catalyzed aminocarbonylation of aryl iodides $\mathbf{1 3}$ in the presence of DMF as a source of $\mathrm{CO}$ and $\mathrm{N}, \mathrm{N}$-dimethylamino groups, investigated in 2008 by Bhanage et al. [32]. For each carbonylated product 14, the yield after column chromatography purification is reported in brackets.

In a subsequent study, Bhanage et al. proposed, instead, the aminocarbonylation of aryl iodides 15 and bromides 16 with DMF as a CO source [33]. In this case, authors returned to the use of a homogeneous catalytic system, i.e., $\mathrm{Pd}(\mathrm{OAc})_{2}$ in combination with Xantphos as a ligand. In the case of iodides 15, carbonylation was carried out with $3 \mathrm{~mol} \%$ of $\mathrm{Pd}(\mathrm{OAc})_{2}, 6 \mathrm{~mol} \%$ of Xantphos, 2.0 equiv. of $\mathrm{POCl}_{3}$, in $\mathrm{DMF}$ at $135{ }^{\circ} \mathrm{C}$ for $6 \mathrm{~h}$, affording the corresponding $\mathrm{N}, \mathrm{N}$-dimethylbenzamide products 17 in $78-93 \%$ yields; with less reactive bromides 16, higher catalytic loading ( $5 \mathrm{~mol} \%$ of $\mathrm{Pd}(\mathrm{OAc})_{2}, 10 \mathrm{~mol} \%$ of Xantphos) and temperature $\left(165^{\circ} \mathrm{C}\right)$ and longer reaction times $(24 \mathrm{~h})$ were required to obtain amides 18 in $64-76 \%$ yields (Scheme 7). The protocol proved to be effective over a broad substrate scope, bearing electron-donating or electron-withdrawing groups in the para or ortho positions. It is worth emphasizing that, in this study, no mechanistic investigations were performed, although we can still hypothesize a similar path to that described by Hiyama and Nozaki (see Scheme 5). 


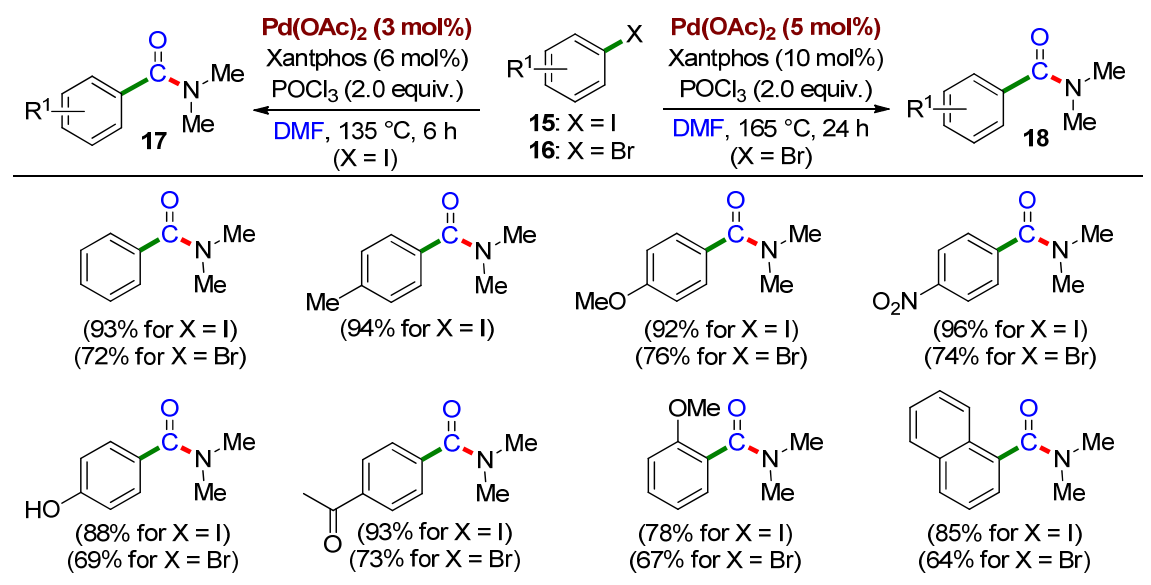

Scheme 7. Pd-catalyzed aminocarbonylation of aryl iodides 15 and bromides $\mathbf{1 6}$ with DMF as a CO source, proposed in 2011 by Bhanage et al. [33]. For each carbonylated product 17-18, the yield after column chromatography purification is reported in brackets.

Despite aminocarbonylation representing the most common class of Pd-catalyzed carbonylation involving DMF as a CO surrogate, more recently a photocatalytic carbonylative Suzuki-Miyaura coupling of aryl iodides $\mathbf{1 9}$ with aryl boronic acids $\mathbf{2 0}$ was achieved by Li et al. [34]. Under the optimized experimental conditions, reactions were carried out with 2.0 equiv. of boronic acid 20, in the presence of $\mathrm{Pd}(\mathrm{phen}) \mathrm{Cl}_{2}(3 \mathrm{~mol} \%)$ and $\mathrm{TiO}_{2}$ as the catalysts, 10 equiv. of $\mathrm{Et}_{3} \mathrm{~N}$ as the base, under $\mathrm{UV}$ irradiation at $365 \mathrm{~nm}$ and a $\mathrm{CO}_{2}$ atmosphere, in a toluene/DMF/ $\mathrm{H}_{2} \mathrm{O}$ solvent mixture, affording diaryl ketones 21 (Scheme 8). The substrate scope was actually very limited, affording a maximum yield of $45 \%$ of diaryl ketones 21 , since this study only represents a proof-of-concept, rather than an extended synthetic investigation: in our opinion, further investigation would be needed to increase the impact of this protocol in the context of organic chemistry.

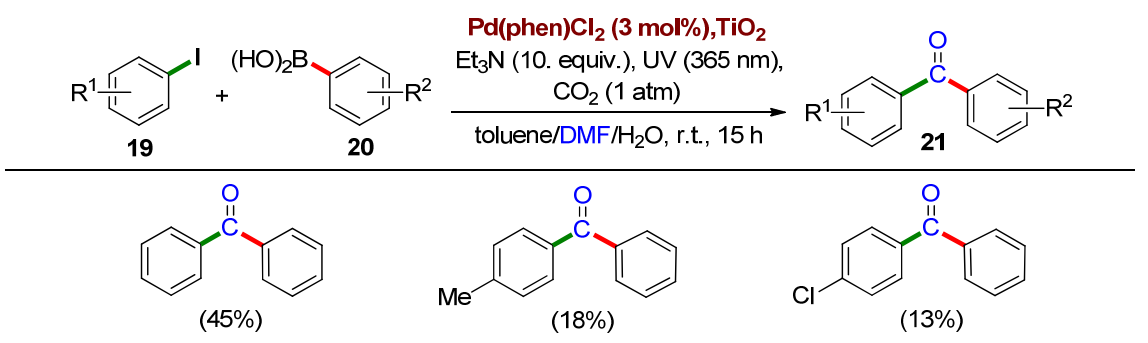

Scheme 8. Pd-catalyzed photocatalytic carbonylative Suzuki-Miyaura coupling of aryl iodides 19 with aryl boronic acids 20, achieved in 2017 by Li et al. [34]. For each carbonylated product 21, yield is reported in brackets.

A simplified reaction mechanism proposed by the authors for this carbonylative transformation is depicted in Scheme 9. Under UV irradiation, $\mathrm{TiO}_{2}$ allowed for the photocatalytic decomposition of DMF to $\mathrm{CO}$, which was then involved in a carbonylative Suzuki-Miyaura coupling promoted by the palladium species: the starting $\operatorname{Pd}(0)$ species gave oxidative addition on the aryl iodide 19, affording the arylpalladium(II) intermediate 22; then, the photocatalytically in-situ-generated $\mathrm{CO}$ was coordinated by the $\mathrm{Pd}(\mathrm{II})$ of intermediate 22, generating the corresponding aroylpalladium(II) complex 23; the subsequent $\mathrm{Et}_{3} \mathrm{~N}$-promoted transmetalation of arylboronic acid $\mathbf{2 0}$ gave a new $\mathrm{Pd}(\mathrm{II})$ intermediate $\mathbf{2 4}$, which generated the final diaryl ketone product 21 and the starting $\operatorname{Pd}(0)$ species after the reductive elimination step. It is worth emphasizing that the modest yields of the carbonylated products 21 were due to the modest amounts of $\mathrm{CO}$ generated via the photocatalytic decomposition of DMF, as well as to the concomitant path of the standard Suzuki-Miyaura coupling, affording the corresponding not carbonylated biaryl products. 


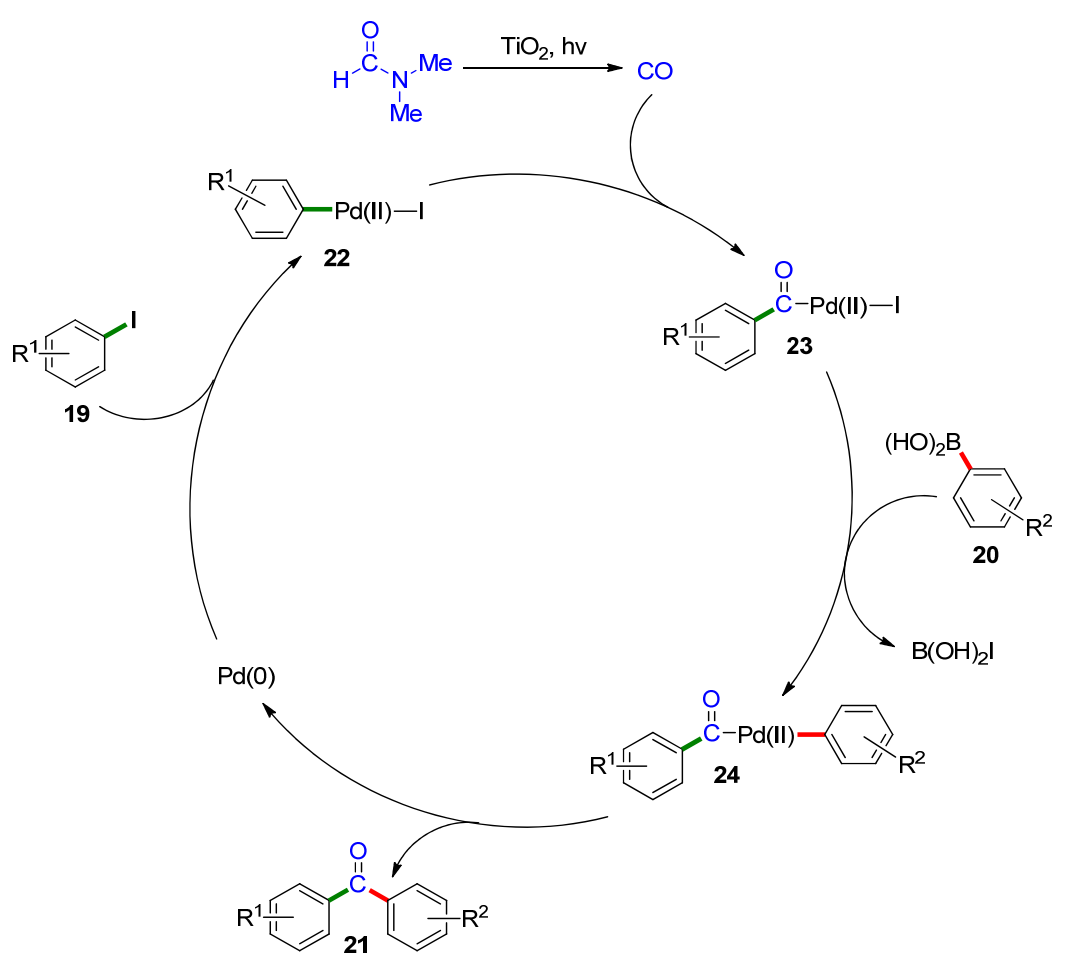

Scheme 9. Simplified proposed reaction mechanism for the Pd-catalyzed photocatalytic carbonylative Suzuki-Miyaura coupling of aryl iodides 19 with aryl boronic acids 20, reported in 2017 by Li et al. [34].

\subsection{Nickel-Catalyzed Carbonylation Involving DMF as a CO Surrogate}

In the periodic table, nickel is placed in the same group as palladium (that is, group 10); therefore, it should not be surprising that it is able to perform most of the same elemental reactions as palladium. Although nickel species are often used as a low-cost alternative to palladium catalysts in the context of carbon-carbon bond formation reactions, they can actually give rise to different mechanistic pathways $[35,36]$. Therefore, it should not be surprising that carbonylation reactions involving the use of DMF as a formal source of carbon monoxide have also been reported in the presence of a nickel catalyst.

The first study in this field was reported in 2007 by Lee and co-workers, who described the aminocarbonylation of aryl iodides/bromides 25, using DMF as the source of $\mathrm{CO}$ and $\mathrm{N}, \mathrm{N}$-dimethylamino groups [37]. After an extended optimization of the experimental conditions, where different nickel species and ligands were tested, reactions were performed with $\mathrm{Ni}(\mathrm{OAc})_{2} \cdot 4 \mathrm{H}_{2} \mathrm{O}(5 \mathrm{~mol} \%)$ and tris(2,4-di-t-butylphenyl)phosphite ( $5 \mathrm{~mol} \%$ ) as a catalytic system, $\mathrm{NaOMe} \mathrm{(4.0} \mathrm{equiv.)} \mathrm{as} \mathrm{a} \mathrm{base,} \mathrm{in} \mathrm{a} \mathrm{DMF/1,4-dioxane} \mathrm{(1:6}$ $v / v$ ) mixture, at $110{ }^{\circ} \mathrm{C}$ for $12 \mathrm{~h}$, affording the corresponding benzamides 26 , in most cases in very good yields (Scheme 10). Interestingly, the protocol showed a broad substrate scope, although aryl halides bearing electron-withdrawing functional groups worked worse than systems with electron-donating groups. By comparing this protocol with the analogous $\mathrm{Pd}(\mathrm{OAc})_{2}$-catalyzed studies described in Section 2.1, in general we found a quite similar performance (in terms of reaction times and product yields), but with the difference that $\mathrm{Ni}(\mathrm{OAc})_{2} \cdot 4 \mathrm{H}_{2} \mathrm{O}$ is much less expensive than $\mathrm{Pd}(\mathrm{OAc})_{2}$. 


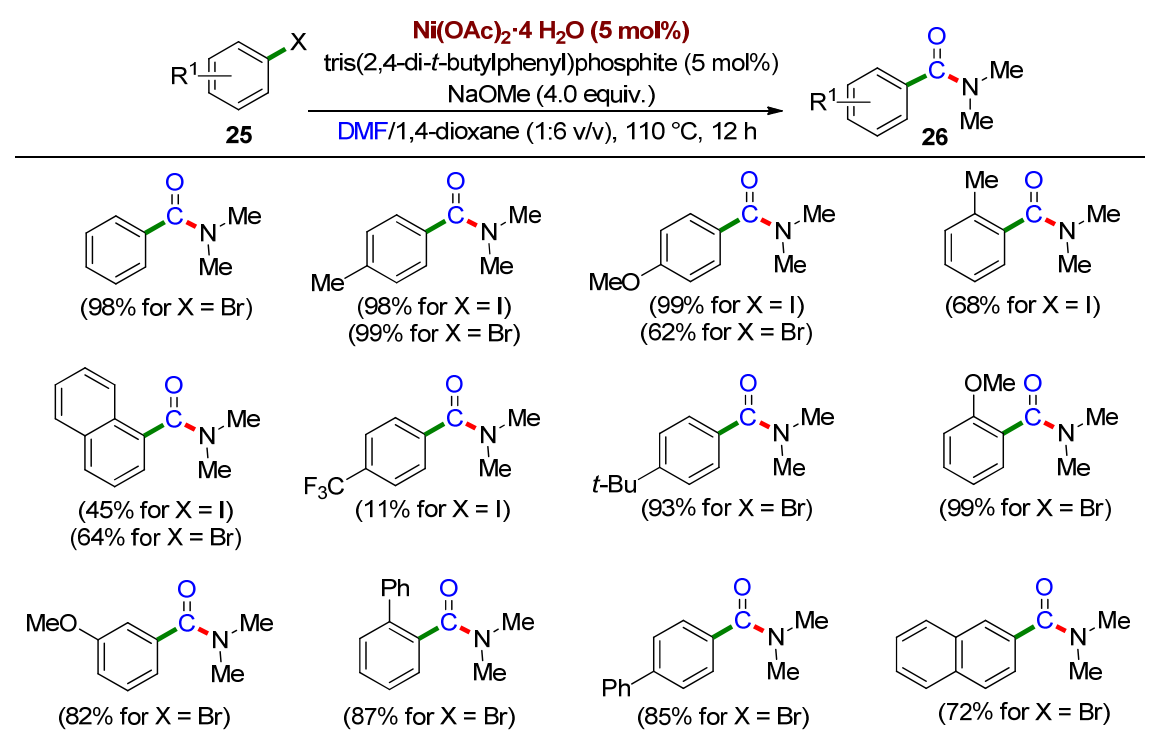

Scheme 10. Ni-catalyzed aminocarbonylation of aryl iodides/bromides 25 , using DMF as the source of $\mathrm{CO}$ and $\mathrm{N}, \mathrm{N}$-dimethylamino groups, reported in 2007 by Lee and co-workers [37]. For each carbonylated product $\mathbf{2 6}$, yield after column chromatography purification was reported in brackets.

Concerning the reaction mechanism, the authors excluded the occurrence of a path similar to that previously reported by Hallberg, Alterman et al. for the analogous palladiumcatalyzed aminocarbonylation (see Scheme 3 ). In fact, by adding imidazole and benzylamine as a further coupling partner, no formation of the corresponding $N$-benzyl amide was found. Therefore, the proposed mechanism was depicted in Scheme 11, consisting of two possible pathways: the first one, starting from the nickel-coordinated alkoxide-DMF adduct 27, which could then give elimination of $\mathrm{MeOH}$ and subsequent formation of a nickel amido intermediate 28 , affording the final amide product 26 by through reductive elimination (Scheme 11a); the other one, working through an aryl group insertion into nickel-coordinated DMF to give the intermediate $\mathbf{2 9}$, followed by a $\beta$-hydrogen elimination step (Scheme 11b).

(a)

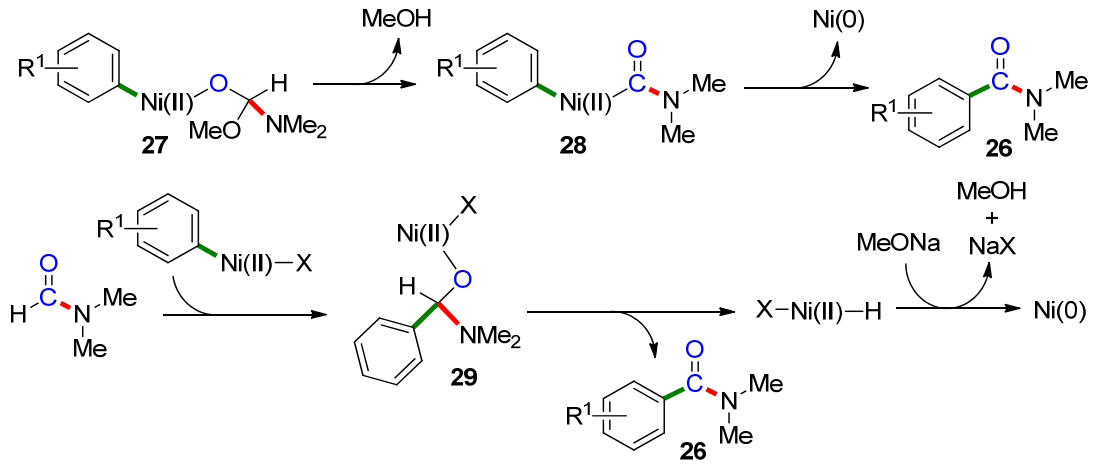

Scheme 11. Simplified proposed reaction mechanism for the Ni-catalyzed aminocarbonylation of aryl iodides/bromides 25, using DMF as the source of $\mathrm{CO}$ and $\mathrm{N}, \mathrm{N}$-dimethylamino groups, reported in 2007 by Lee and co-workers [37].

In a following study, where Lee and co-workers extended the Ni-catalyzed aminocarbonylation of aryl bromides to other formamides, few selected examples involving the use of DMF were also reported [38]. The reaction conditions were almost the same as in the preceding work, with the only difference of using diglyme as a solvent instead of 1,4-dioxane.

More recently, a different nickel-catalyzed carbonylative reaction was reported: $\mathrm{Lu}$, Liu and co-workers described the carbonylative homo-coupling of aryl boronic acids $\mathbf{3 0}$ 
with DMF as a CO surrogate [39]. Interestingly, in the optimization of the experimental conditions several metals have been tested, including $\mathrm{FeCl}_{3}, \mathrm{CuCl}_{2}$ and $\mathrm{CoCl}_{2}$, but no reaction occurred; among nickel species, the best conditions were obtained in the presence of $\mathrm{NiBr}_{2}$. diglyme ( $5 \mathrm{~mol} \%$ ) as catalytic precursor and bis(2,6-diisopropylphenyl)imidazol2-ylidene hydrochloride $(10 \mathrm{~mol} \%)$ as a ligand. Reactions were carried out in the presence of 2.0 equiv. of $\mathrm{KHCO}_{3}$ as base, in DMF at $100{ }^{\circ} \mathrm{C}$ for $14 \mathrm{~h}$, affording the corresponding symmetric diaryl ketones 31 in a $52-92 \%$ yield (Scheme 12). The protocol was successfully applied to substrates with different stereo-electronic properties, bearing electron-poor or electron-rich functional groups in the para, meta and/or ortho positions. One of the major drawbacks of this synthetic procedure was the possibility of application only to the synthesis of symmetric diaryl ketones: in fact, no attempt to prepare asymmetric ketones with the combined use of two different aryl boronic acids was reported.

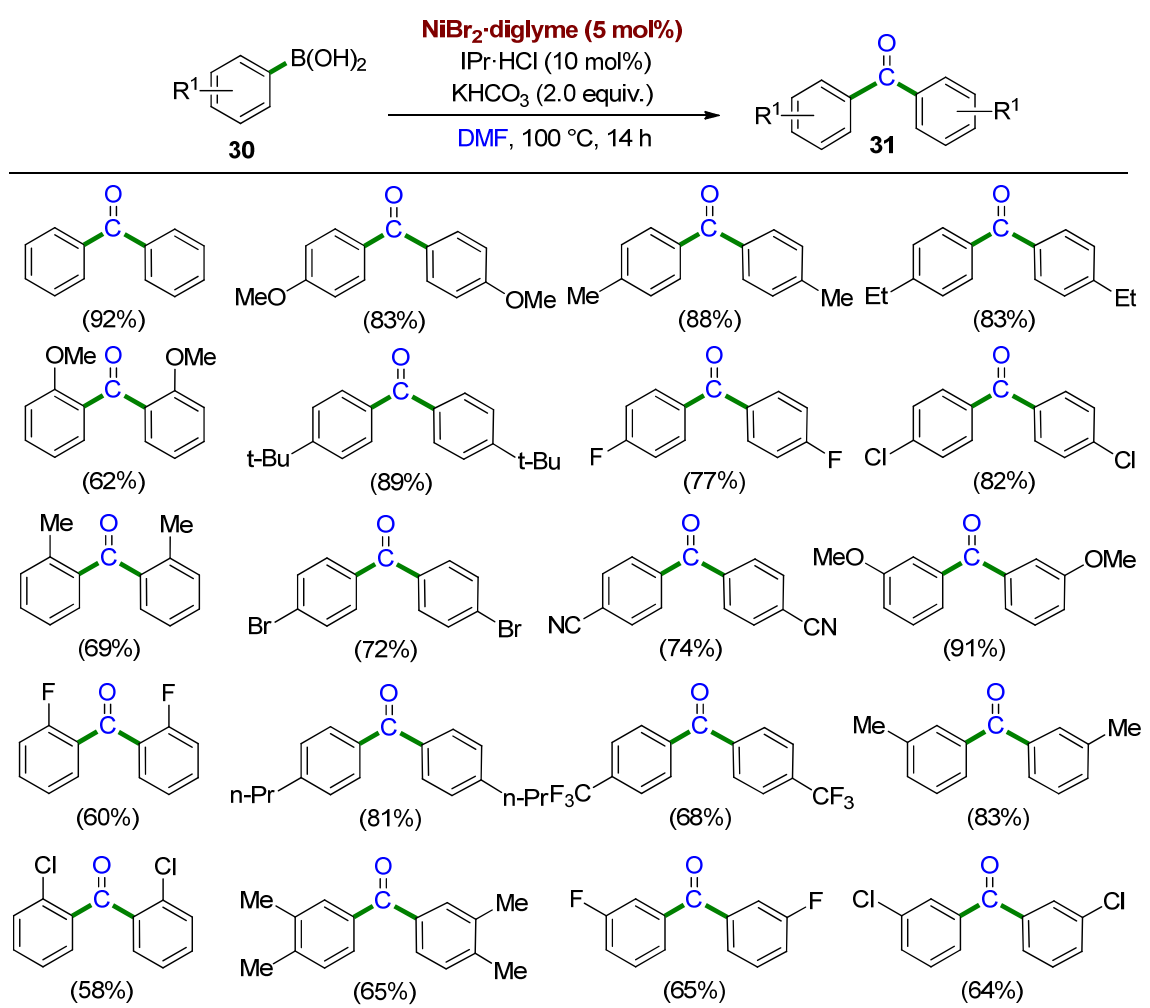

Scheme 12. Ni-catalyzed carbonylative homo-coupling of aryl boronic acids 30 with DMF as a CO surrogate, reported in 2017 by Lu, Liu and co-workers [39]. For each carbonylated product 31, yield after column chromatography purification is reported in brackets.

The authors also proposed a plausible reaction mechanism for this transformation (Scheme 13). First of all, DMF worked as a reducing agent [40] allowing for the reduction of the starting $\mathrm{Ni}(\mathrm{II})$ species to $\mathrm{Ni}(0)$, which gave, then, an oxidative addition on the $\mathrm{C}-\mathrm{H}$ bond of DMF to give intermediate 32. A base-assisted transmetalation of aryl boronic acid 30 afforded the arylnickel(II) complex 33, which then led to the formation of the starting $\mathrm{Ni}(0)$ species and $\mathrm{N}, \mathrm{N}$-dimethylbenzamide intermediate 34 after reductive elimination. At this point, a new oxidative addition of $\mathrm{Ni}(0)$ on the $\mathrm{C}-\mathrm{N}$ bond of 34 gave the corresponding $\mathrm{Ni}$ (II) intermediate 35, subjected to a further transmetalation of aryl boronic acid $\mathbf{3 0}$ giving the complex 36; the final reductive elimination afforded the desired ketone 31 and the starting $\mathrm{Ni}(0)$ complex. 


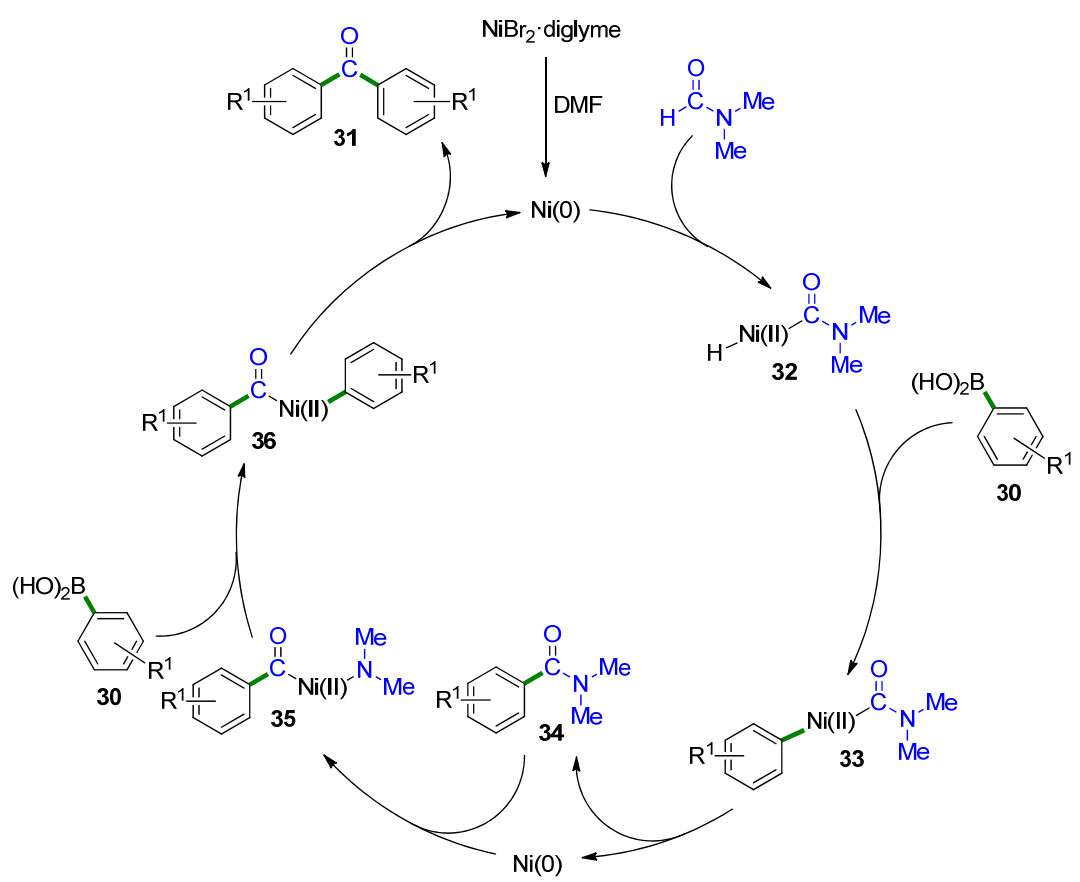

Scheme 13. Proposed reaction mechanism for the Ni-catalyzed carbonylative homo-coupling of aryl boronic acids 30 with DMF as a CO surrogate, reported in 2017 by Lu, Liu and co-workers [39].

3. Synthesis of Heterocycles by Transition Metal-Catalyzed Carbonylation Reactions Involving DMF as a CO Surrogate

3.1. Synthesis of Heterocycles by Palladium-Catalyzed Carbonylation Involving DMF as a CO Surrogate

As described in Section 2.1, most of the carbonylative protocols involving DMF as a CO surrogate were carried out in the presence of a palladium catalyst. Although the aforementioned studies were only applied to the synthesis of acyclic compounds, they well showed the central role played by palladium species in promoting these processes. Therefore, it should not be surprising that most of the synthesis of heterocycles by cyclocarbonylative reactions involving DMF as a CO surrogate reported to date are based on palladium catalysts.

The first study was described in 2015 by Wu and co-workers [41]: a palladium-catalyzed carbonylative cyclization of $\mathrm{N}$-arylpyridin-2-amines 37 by $\mathrm{C}-\mathrm{H}$ activation/annulation using $\mathrm{DMF}$ as a CO surrogate, affording quinazolinones $\mathbf{3 8}$ as the final products, which are typical structural motif in many pharmaceuticals and agrochemicals. Under optimized conditions, reactions were carried out by using $\mathrm{Pd}(\mathrm{OAc})_{2}(5-10 \mathrm{~mol} \%)$ as the catalytic system under ligandless conditions, potassium persulfate (2-3 equiv.) as the oxidant, DMF acting as both reagent and solvent and trifluoroacetic acid as the co-solvent, at $140{ }^{\circ} \mathrm{C}$ under an $\mathrm{O}_{2}$ atmosphere (Scheme 14). Interestingly, some formamide analogues of DMF were also tested as an alternative source of $\mathrm{CO}$, but only low yields of the resulting quinazolinones products were obtained. Concerning the substrate scope, $\mathrm{N}$-arylpyridin-2amines 37 bearing several functional groups on the benzene ring have been tested. Electrondonating substituents (i.e., methyl, phenyl, benzyloxy, dimethylamino and methylthio), as well as electron-withdrawing groups (like trifluoromethoxy and acetyl) were well tolerated, and the corresponding products were obtained in good to excellent yields. More interestingly, substrates bearing in the para, meta and/or ortho positions one or more halogen atoms, which are typically reactive in many palladium-catalyzed reactions, including the above described carbonylation reactions involving the use of DMF as a CO surrogate (see Section 2.1), were also compatible with the developed experimental conditions, affording the related quinazolinones products $\mathbf{3 8}$ in good yields. 


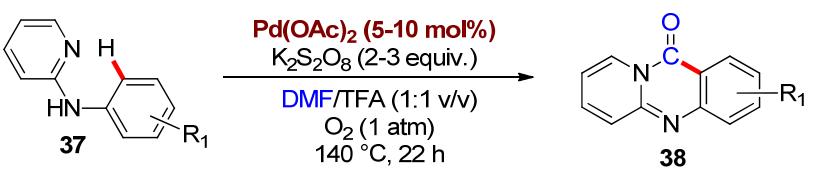<smiles>O=c1c2ccccc2nc2ccccn12</smiles>

(79\%)<smiles>Cc1ccc2nc3ccccn3c(=O)c2c1</smiles>

(92\%)<smiles>CN(C)c1ccc2nc3ccccn3c(=O)c2c1</smiles>

(65\%)<smiles>CC(C)(C)c1ccc2nc3ccccn3c(=O)c2c1</smiles>

(46\%)<smiles>O=c1c2cc(Br)ccc2nc2ccccn12</smiles>

(51\%)<smiles>O=c1c2c(Cl)cccc2nc2ccccn12</smiles>

(50\%)<smiles>O=c1c2cc(F)ccc2nc2ccccn12</smiles>

(62\%)<smiles>O=c1c2cccc(I)c2nc2ccccn12</smiles>

(69\%) Cl<smiles>O=c1c2cc(-c3ccccc3)ccc2nc2ccccn12</smiles>
$(93 \%)$<smiles>CCCCOc1ccc2nc3ccccn3c(=O)c2c1</smiles><smiles>O=c1c2cc(OC(F)(F)F)ccc2nc2ccccn12</smiles>
(42\%)<smiles>CC(=O)c1ccc2nc3ccccn3c(=O)c2c1</smiles><smiles>O=c1c2cc(Cl)ccc2nc2ccccn12</smiles>
(70\%)<smiles>Cc1ccc2c(=O)n3ccccc3nc2c1</smiles><smiles>CCc1cccc2c(=O)n3ccccc3nc12</smiles>
(85\%) Ph<smiles>Cc1ccc([N+](=O)[O-])c2nc3ccccn3c(=O)c12</smiles>

(73\%) Me

Scheme 14. Pd-catalyzed carbonylative cyclization of $N$-arylpyridin-2-amines 37 using DMF as a $\mathrm{CO}$ surrogate for the synthesis of quinazolinones 38, reported in 2015 by Wu and co-workers [41]. For each heterocyclic carbonylated product, the yield after chromatographic purification is reported in brackets.

The reaction mechanism proposed by the authors (Scheme 15) clearly highlights the role played by the $\mathrm{Pd}(\mathrm{OAc})_{2}$ catalyst. First of all, the coordination of the palladium(II) species to the substrate molecule 37 followed by the $\mathrm{C}-\mathrm{H}$ activation step on the ortho position of the benzene ring afforded the $\mathrm{Pd}(\mathrm{II})$ complex 39. The combined effect of high temperatures and trifluoroacetic acid allowed for the decomposition of DMF and subsequent in-situ release of $\mathrm{CO}$, which was then coordinated to complex 39 , giving the metal carbonyl intermediate 40. The insertion of carbon monoxide into the $\mathrm{Pd}-\mathrm{C}$ bond gave the acylpalladium(II) complex $\mathbf{4 1}$, followed by the reductive elimination step which afforded the final heterocyclic product 38 and a palladium( $(0)$ species. The occurrence of both $\mathrm{K}_{2} \mathrm{~S}_{2} \mathrm{O}_{8}$ and $\mathrm{O}_{2}$ as oxidants was mandatory to close the catalytic cycle, since they allowed for the re-oxidation of $\mathrm{Pd}(0)$ to the starting $\mathrm{Pd}(\mathrm{II})$ catalyst. In order to confirm that DMF was the effective source of $\mathrm{CO}$, the authors also performed some tests of carbonylative cyclization using a ${ }^{13} \mathrm{CO}$-labeled DMF. 


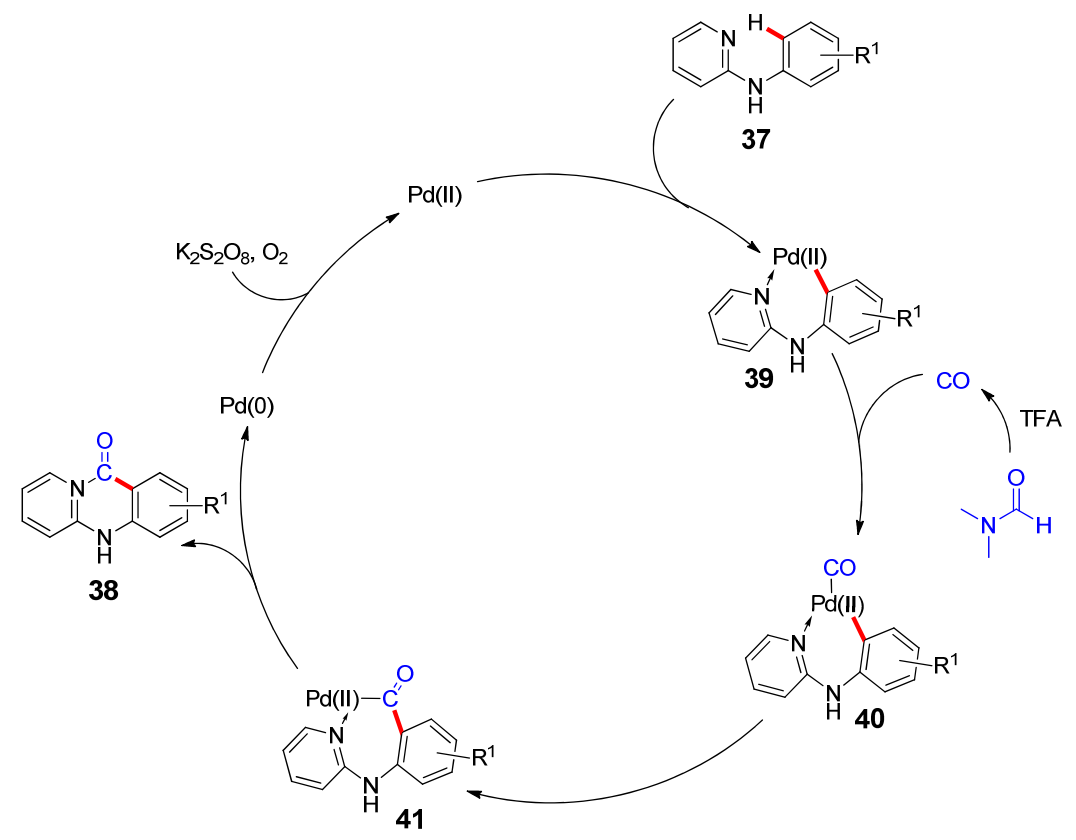

Scheme 15. Proposed reaction mechanism for the synthesis of quinazolinones 38 by Pd-catalyzed carbonylative cyclization of $N$-arylpyridin-2-amines 37 using DMF as a CO surrogate, reported in 2015 by $\mathrm{Wu}$ and co-workers [41].

The above-described protocol from $\mathrm{Wu}$ and co-workers offers many food for thought. The use of palladium(II) acetate as the catalytic system is definitely convenient, as it is quite inexpensive (especially compared to many other Pd species) and does not require the use of ligands, which instead are typically used in the analogous synthesis of quinazolinones by traditional cyclocarbonylative reactions with carbon monoxide [42]. However, high metal loading was required (5-10 $\mathrm{mol} \%$ ), thus forcing tedious purification procedures of the quinazolinone products in order to remove palladium traces, especially when involved in the synthesis of pharmaceuticals and agrochemicals $[43,44]$. Despite the synergistic use of $\mathrm{K}_{2} \mathrm{~S}_{2} \mathrm{O}_{8}$ and $\mathrm{O}_{2}$ as mild and inexpensive oxidizing agents, unfortunately the protocol required hard experimental conditions based on high temperatures for long reaction times, which hardly fit with the principles of the Green Chemistry (in particular with Principle 6: Design for Energy Efficiency) [45,46]. It is worth emphasizing that such protocol offered a broad substrate scope, affording highly functionalized quinazolinones; in particular, the halo-substituted products were very appealing, as they could be further functionalized by transition metal-catalyzed cross-coupling reactions on the $\mathrm{C}-\mathrm{X}$ bonds $[47,48]$.

A possible way to improve the sustainability and the impact of palladium-catalyzed cyclocarbonylative reactions is represented by the use of supported catalysts, as they can be easily recovered and reused many times, thus avoiding the problematic metal contamination of cyclization products which typically occurred with homogeneous catalytic systems [49-52]. In this context, Wu et al. developed, in 2015, an appealing improvement of their previous work on the carbonylative cyclization of $\mathrm{N}$-arylpyridin-2-amine derivatives 42 by $\mathrm{C}-\mathrm{H}$ activation/ annulation with $\mathrm{DMF}$ as a $\mathrm{CO}$ surrogate, using $\mathrm{Pd} / \mathrm{C}$ as supported catalyst [53]. It is worth emphasizing that the authors also tested the use of $\mathrm{Cu}(\mathrm{acac})_{2}$ as a co-catalyst during the optimization of the reaction conditions; since direct $\mathrm{C}-\mathrm{H}$ bond arylation of (hetero)arenes are often performed with bimetallic $\mathrm{Pd} / \mathrm{Ag}$ [54] or Pd/Cu [55] catalytic systems, the use of $\mathrm{Cu}(\mathrm{acac})_{2}$ in combination with $\mathrm{Pd} / \mathrm{C}$ could help the starting of the $\mathrm{C}-\mathrm{H}$ activation step. However, in this specific case no improvements in the quinazolinones $\mathbf{4 3}$ yields were observed in the presence of copper species, so its use was then set aside in the optimized experimental conditions. In fact, reactions were carried out by using commercial $10 \mathrm{wt} . \% \mathrm{Pd} / \mathrm{C} \mathrm{(5} \mathrm{mol} \%)$ as the catalyst, 3.0 equiv. of $\mathrm{K}_{2} \mathrm{~S}_{2} \mathrm{O}_{8}$ and $\mathrm{O}_{2}$ (1 atm) as oxidizing agents, DMF as both $\mathrm{CO}$ source and solvent and $\mathrm{CF}_{3} \mathrm{COOH}$ as the 
co-solvent, at $140{ }^{\circ} \mathrm{C}$ for $5-24 \mathrm{~h}$ (Scheme 16). The substrate scope was quite similar to that of the previous study: reactions were carried out on $N$-arylpyridin- 2-amines 42 with both electron-donating and electron-withdrawing groups on the benzene ring, affording the corresponding quinazolinones $\mathbf{4 3}$ in moderate-to-good yields. Notably, this new protocol generally showed lower reaction times, in particular in the case of electron-rich substrates.

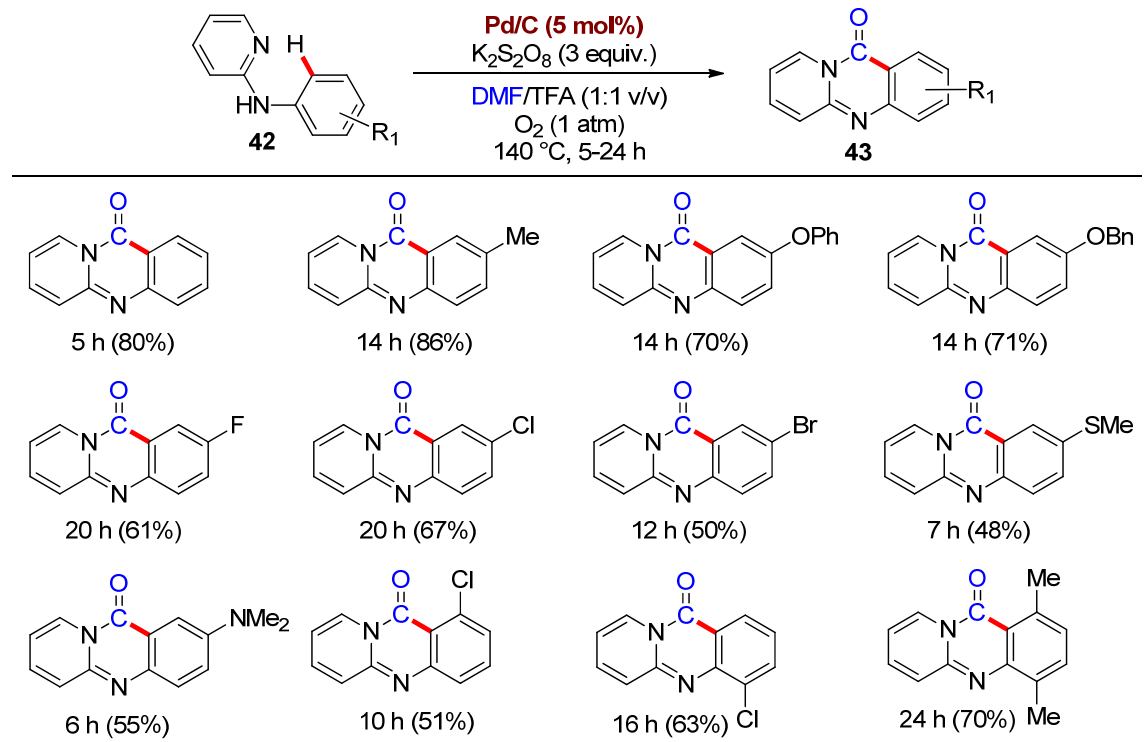

Scheme 16. Synthesis of quinazolinones 43 through carbonylative cyclization of $N$-arylpyridin-2amines 42 with DMF as a CO surrogate catalyzed by Pd/C, developed in 2015 by Wu et al. [53]. For each heterocyclic product, reaction time and yield after chromatographic purification (in brackets) are reported.

Concerning the mechanism, authors proposed the same catalytic cycle: (i) $\mathrm{C}-\mathrm{H}$ activation on the ortho position of $\mathrm{N}$-arylpyridin-2-amine 42 substrate by a $\mathrm{Pd}(\mathrm{II})$ species; (ii) thermal- and acid-mediated DMF decomposition to $\mathrm{CO}$, followed by its coordination to $\mathrm{Pd}(\mathrm{II})$; (iii) $\mathrm{CO}$ insertion on the $\mathrm{Pd}-\mathrm{C}$ bond to give an acylpalladium(II) complex; (iv) reductive elimination of the acylpalladium(II) intermediate, affording quinazolinone 43 and a $\operatorname{Pd}(0)$ species; (v) oxidation of $\operatorname{Pd}(0)$ to the starting $\operatorname{Pd}(\mathrm{II})$ species, by the combined effect of $\mathrm{K}_{2} \mathrm{~S}_{2} \mathrm{O}_{8}$ and $\mathrm{O}_{2}$. In order to confirm that DMF was the effective source of $\mathrm{CO}$, also in this case a carbonyl- ${ }^{13} \mathrm{C}$ labeled DMF was used in a representative example of carbonylative cyclization of $\mathrm{N}$-phenyl pyridin-2-amine 44, affording the corresponding $11 H$-pyrido[2,1-b]quinazolin-11-one-11-13 C 45 at $28 \%$ yield (Scheme 17).
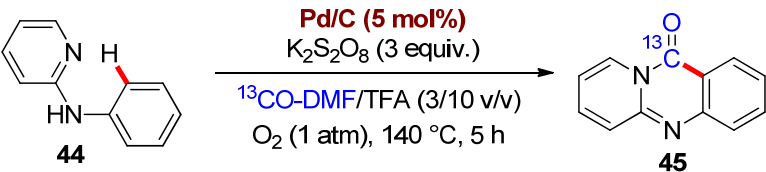

$28 \%$ GC yield

confirmed by

45

Scheme 17. Pd/C-catalyzed carbonylative cyclization of $N$-phenyl pyridin-2-amine 44 using carbonyl${ }^{13}$ C-labeled DMF: synthesis of $11 H$-pyrido[2,1-b]quinazolin-11-one-11-13 C 45.

The use of commercial and inexpensive $\mathrm{Pd} / \mathrm{C}$ as a catalyst in the present protocol offered major improvements in the preparation of quinazolinones; although the same temperature was used here $\left(140^{\circ} \mathrm{C}\right)$, a significant decrease of the reaction times was observed for several substrates, thus limiting the energy requirements of the process; moreover, such catalytic system avoids - at least in theory-the metal contamination of carbocyclization products, as it is easily recoverable at the end of the reaction by simply filtration. However, in this work $\mathrm{Wu}$ and co-workers did not investigate the nature of the catalytic mechanism, i.e., heterogeneous vs. homogeneous. In the absence of Maitlis 
hot filtration tests and/or metal leaching measurements by ICP analysis [56,57], it is not possible to understand whether catalytically active palladium species remained supported on the carbon matrix, or whether they were leached into the solution under the reaction conditions. The authors only reported that their attempts of recycling $\mathrm{Pd} / \mathrm{C}$ catalyst for a 2nd run after filtration were always unsuccessful. They hypothesized a poorly defined catalyst deactivation caused by the strong acid conditions of TFA, although a severe metal leaching into the solution cannot be excluded.

Although both protocols of $\mathrm{Wu}$ and co-workers were characterized by a quite extended substrate scope, they were limited to the synthesis of quinazolinones as the only heterocycles. Due to the above-mentioned advantages of DMF, it could be interesting the development of new Pd-catalyzed carbonylative cyclization protocols involving DMF as a $\mathrm{CO}$ surrogate for the synthesis of other highly functionalized heterocycles. In this context, in 2016 Das et al. described an unprecedented Pd/Ag bimetallic catalysis for the synthesis of pyrido-fused quinazolinones and phenanthridinones by aerobic cyclocarbonylation in the presence of DMF as the carbon source [58]. Concerning the catalytic system, several metal species were tested in the optimization of the reaction conditions. First, keeping $\mathrm{Pd}(\mathrm{OAc})_{2}$ as the main catalyst, many silver compounds were tested as co-catalysts (i.e., $\mathrm{Ag}_{2} \mathrm{CO}_{3}, \mathrm{Ag}_{2} \mathrm{O}, \mathrm{AgOAc}, \mathrm{Ag}_{2} \mathrm{SO}_{4}, \mathrm{AgF}, \mathrm{AgNO}_{3}, \mathrm{AgSbF}_{6}, \mathrm{AgTFA}$ and AgOTf); although in almost all cases the reaction occurred, the best performance in terms of yields were found using AgOTf. Then, in the presence of AgOTf as the co-catalyst other metal catalysts were tested: $\mathrm{Ni}(\mathrm{OAc})_{2}$, affording the heterocyclic products in low yields, $\mathrm{Cu}(\mathrm{OAc})_{2}$ and $\mathrm{Co}(\mathrm{OAc})_{2}$, which instead gave no reaction. Moreover, the synergistic effect of $\mathrm{Pd}$ and $\mathrm{Ag}$ catalysis was further confirmed by the absence of any reaction using only $\mathrm{Pd}(\mathrm{OAc})_{2}$ or AgOTf. Therefore, under the optimized experimental conditions $\mathrm{N}$-arylpyridin-2-amines 46 and 2-arylanilines 48 were treated with $\mathrm{Pd}(\mathrm{OAc})_{2}(10 \mathrm{~mol} \%)$ and $\mathrm{AgOTf}$ (0.4 equiv.), in DMF acting as both reagent and solvent, under $\mathrm{O}_{2}$ atmosphere at $140^{\circ} \mathrm{C}$ for $24 \mathrm{~h}$, to give quinazolinones 47 and phenanthridinones 49 , respectively.

The substrate scope investigated in this work for the preparation of quinazolinones 47 (Scheme 18) was more extended than the previous protocols of $\mathrm{Wu}$ and co-workers. In fact, reactions were carried out on $\mathrm{N}$-arylpyridin-2-amines 46 functionalized not only on the benzene ring but also on the pyridine scaffold, giving an opportunity to obtain useful building blocks susceptible to further transformations. In particular, the protocol appears highly robust, since heterocyclic products 47 were obtained in high yields $(70-80 \%)$ regardless of the type of substituents (electron-withdrawing and electron-donating). The authors also tested $N$-phenyl pyrimidin-2-amine and $N$-phenyl isoquinolin-1-amine as starting substrates, which afforded the corresponding products in very good yields, thus demonstrating that their protocol could be successfully extended to the synthesis of other classes of heterocycles, including tetracyclic scaffolds. In light of these encouraging results, they then explored the preparation of phenanthridinones 49 (Scheme 19), a typical structural motif in medicinally important compounds. $\mathrm{N}$-methyl 2-arylanilines bearing functional groups with various electronic properties $(-\mathrm{Me},-\mathrm{OMe},-\mathrm{F},-\mathrm{COOMe})$ were well tolerated, giving the corresponding $N$-methyl phenanthridinones at $70-90 \%$ yield; however, 2-arylanilines, without any protection on the aniline moiety, gave $\mathrm{NH}$-free phenanthridinones in lower yields compared with the $\mathrm{N}$-methylated products. 


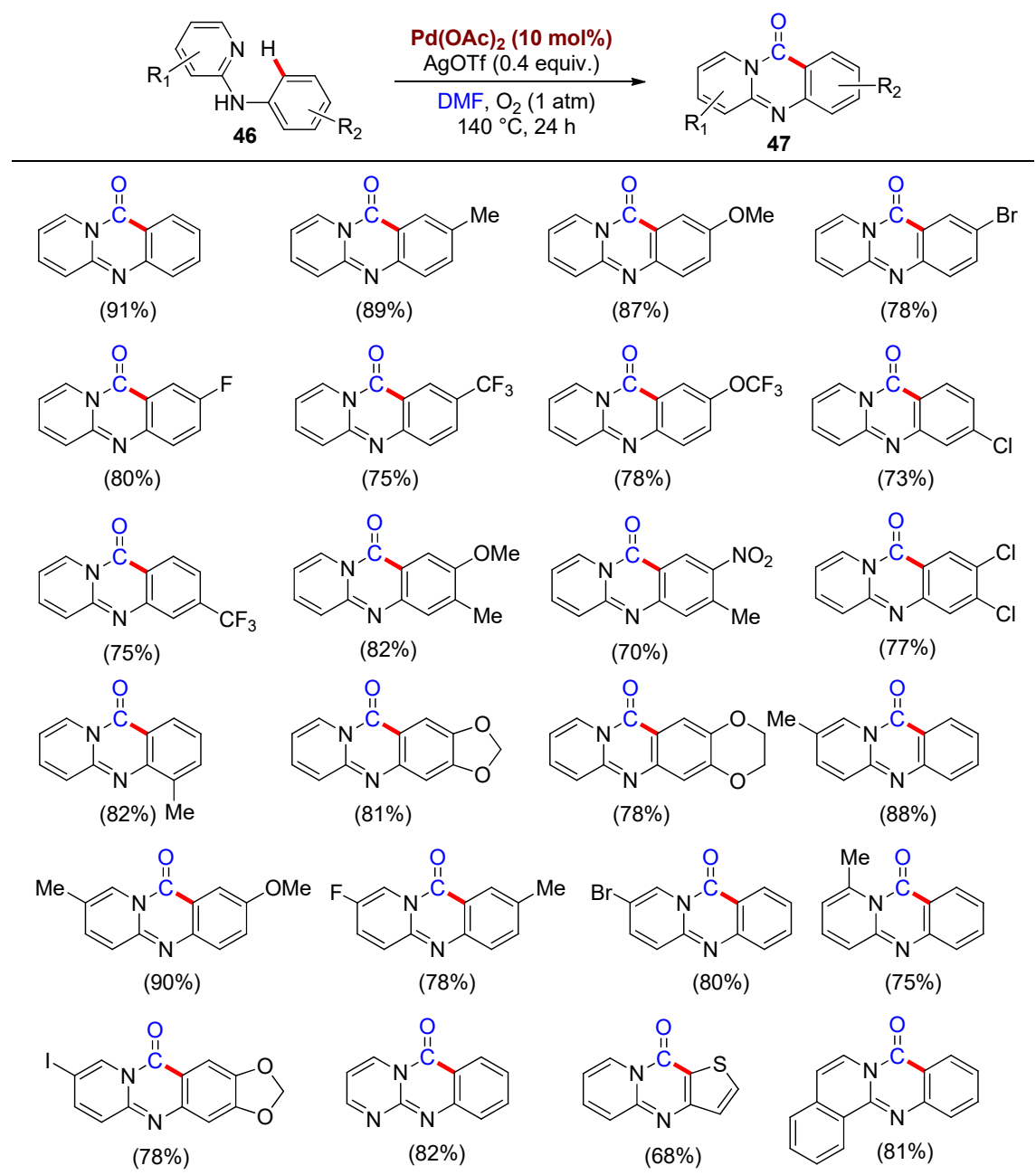

Scheme 18. Synergistic Pd/Ag-catalyzed carbonylative cyclization of $N$-arylpyridin-2-amines 46 using DMF as a CO surrogate for the synthesis of quinazolinones 47, reported in 2016 by Das et al. [58]. For each heterocyclic carbonylated product, the yield after column chromatography purification is reported in brackets.

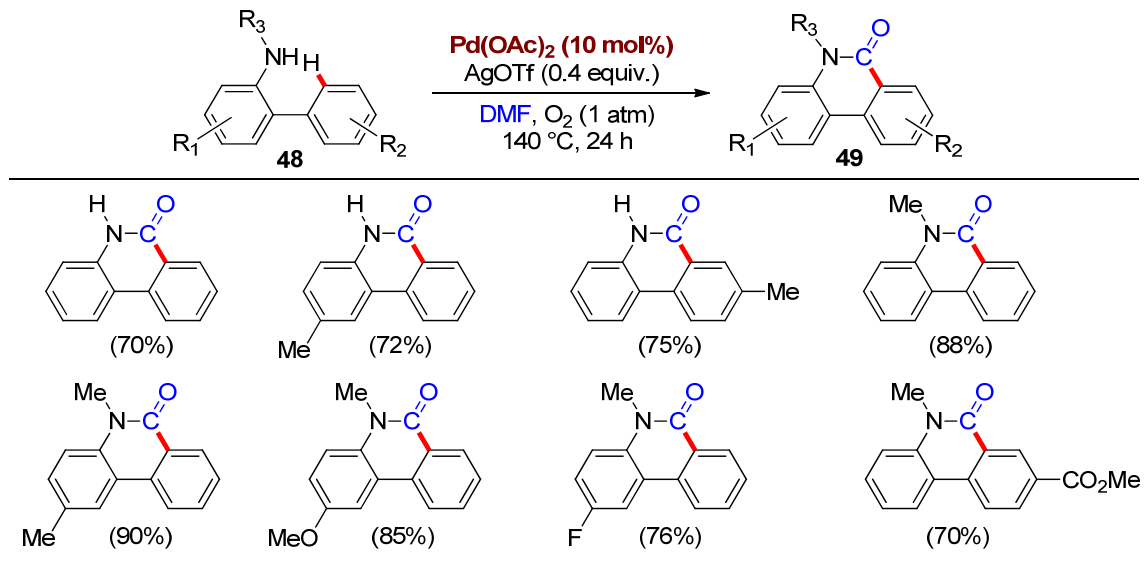

Scheme 19. Synergistic Pd/Ag-catalyzed carbonylative cyclization of N-methyl 2-arylanilines 48 with DMF as a CO surrogate for the synthesis of phenanthridinones 49, reported in 2016 by Das et al. [58]. For each heterocyclic carbonylated product, the yield after column chromatography purification is reported in brackets.

One of the most appealing aspects of this work is the role of DMF as a source of carbon monoxide. In the previous studies of $\mathrm{Wu}$ and co-workers $[41,53]$, carbonyl- ${ }^{13} \mathrm{C}$ - 
labeled DMF experiments confirmed that the $\mathrm{C}=\mathrm{O}$ group of $\mathrm{DMF}$ was the effective source of $\mathrm{CO}$ incorporated in the cyclocarbonylated products. Interestingly, this is not the case of the present study. First, reactions performed with formamide instead of DMF gave no products, thus suggesting that the methyl group of DMF (rather than the carbonyl group) could be involved in the process; second, by using carbonyl ${ }^{18} \mathrm{O}$ labeled DMF in representative experiments no incorporation of ${ }^{18} \mathrm{O}$ in the products was found, confirming that the carbonyl group in the heterocyclic products came from the methyl group of DMF; third, tests performed under an argon atmosphere in the place of $\mathrm{O}_{2}$ provided the cyclocarbonylation products in traces, indicating that $\mathrm{O}_{2}$ was involved in the process as a source of oxygen atoms rather than as a simple oxidizing agent. In other words, in quinazolinones 47 and phenanthridinones 49 obtained with this protocol, the carbon atom of the carbonyl group is derived from the methyl groups of DMF, while the oxygen atom of the carbonyl group originated from $\mathrm{O}_{2}$.

Starting from all these considerations, Das et al. proposed a plausible mechanism for their protocols, well showing the central role of the Pd/Ag synergistic catalysis (Scheme 20). First of all, the starting palladium(II) species was coordinated to the nitrogen atom of the pyridine ring, followed by the $\mathrm{C}-\mathrm{H}$ bond activation step on the ortho position of the benzene ring to afford the $\mathrm{Pd}(\mathrm{II})$ complex 50. Simultaneously, a sequential decarbonylation, nucleophilic addition and elimination of DMF, allowed by a silver(I) catalysis and in the presence of $\mathrm{O}_{2}$ as an oxidizing agent, generated the iminium species 51 . Then, the palladium(II) intermediate $\mathbf{5 0}$ gave a nucleophilic addition to the iminium species $\mathbf{5 1}$, producing the seven-membered palladacycle intermediate 52; the subsequent reductive elimination of such intermediate generated the heterocyclic intermediate 53 and a $\operatorname{Pd}(0)$ species, which was re-oxidized into the starting $\mathrm{Pd}(\mathrm{II})$ in order to close the catalytic cycle by the action of silver(I) and atmospheric $\mathrm{O}_{2}$. The Ag- and $\mathrm{O}_{2}$-assisted oxidation of 53 produced the iminium salts $\mathbf{5 4}$, which, upon hydrolysis, furnished the final product with the elimination of dimethylamine.

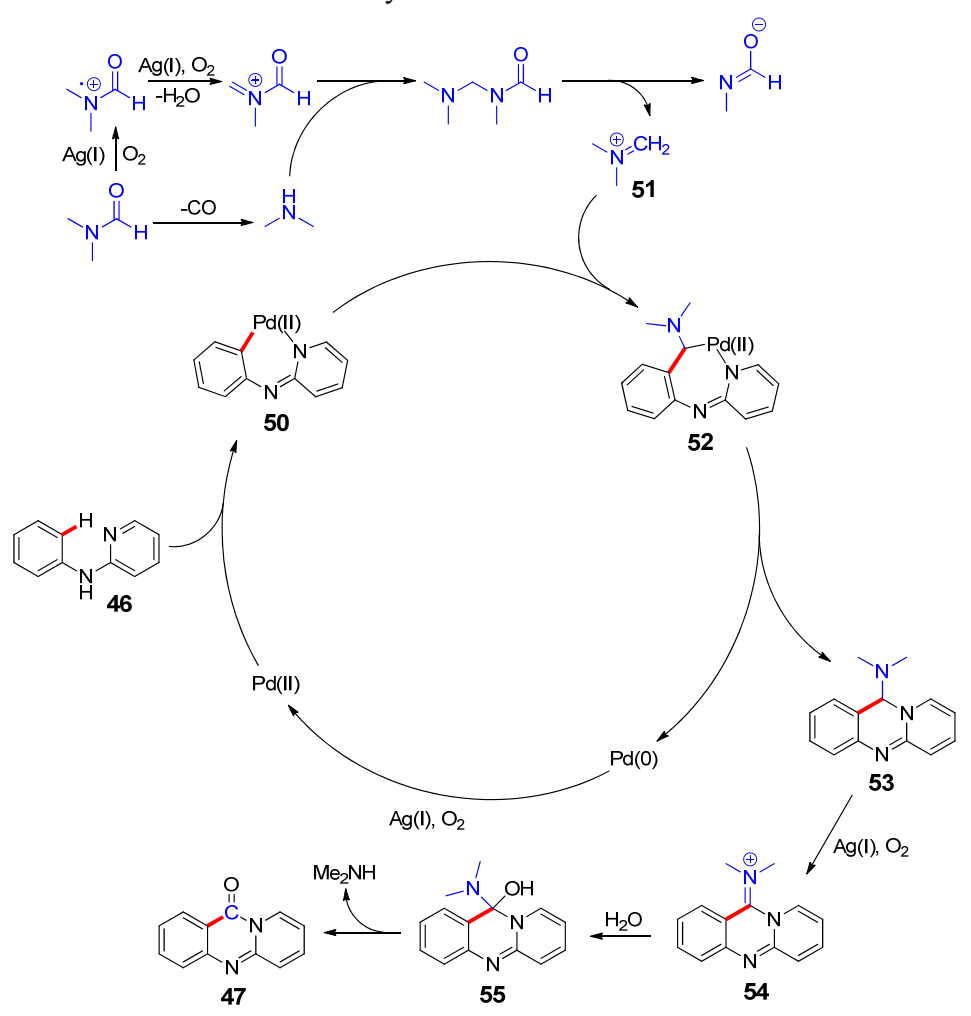

Scheme 20. Proposed reaction mechanism for the synthesis of quinazolinones 47 and phenanthridinones 49 by a $\mathrm{Pd} / \mathrm{Ag}$ synergistic catalyzed carbonylative cyclization of $\mathrm{N}$-arylpyridin-2-amines and $N$-methyl 2- arylanilines using DMF as a CO surrogate, reported in 2016 by Das et al. [58]. 
The above described protocol of Das et al. well highlights some interesting points. First of all, it is clear that DMF in cyclocarbonylative reactions can act as a CO surrogate through different reaction mechanisms: if under a pure palladium catalysis we found that the carbonyl group of DMF was directly the source of $\mathrm{CO}$ (Wu's protocols) [41,53], in this case the synergistic action of palladium and silver catalysis offered a very different pathway, where the methyl group of DMF was the source of the carbon atom of $\mathrm{CO}$, while atmospheric $\mathrm{O}_{2}$ was the source of the oxygen atom. Therefore, DMF represents a very versatile reagent as an alternative, inexpensive and efficient source of $\mathrm{CO}$ in the context of carbonylative reactions: the study of new reaction conditions, and in particular the exploration of other different metal catalysts, could further extend the application of DMF to the synthesis of other classes of heterocycles. In fact, another major advantage of the protocol developed by Das et al. is the possibility of synthesizing not only quinazolinones but also phenanthridinones; there is considerable synthetic interest in this class of heterocycles [59], since they show several appealing applications in the context of medicinal chemistry [60-62].

However, the protocol also has some issues. In addition to the use of a homogeneous $\mathrm{Pd}(\mathrm{OAc})_{2}$ catalyst and AgOTf co-catalyst, which could contaminate the final reaction products (requiring tedious purification procedures in order to remove all the metal traces, especially in the case of agrochemical or medicinal applications), the need of them in high amounts ( $10 \mathrm{~mol} \%$ of $\mathrm{Pd}(\mathrm{OAc})_{2}$ and, in particular, $40 \mathrm{~mol} \%$ of AgOTf) is quite expensive and far afield of the principles of the Green Chemistry. Moreover, the protocol required high temperatures and long reaction times, which also hardly fit with the need to minimize energy requirements. The exploration of other metal catalysts, based on different mechanistic pathways, could represent a valid tool to allow the use of milder and environmentally friendly experimental conditions.

\subsection{Synthesis of Heterocycles by Nickel-Catalyzed Carbonylation Involving DMF as a CO Surrogate}

As described in Section 2.2, some examples of carbonylative protocols involving DMF as a CO surrogate were also carried out in the presence of a nickel catalyst, which is often used as a low-cost alternative to palladium catalysts in the context of carbon-carbon bond formation reactions. Although these studies were only applied to the synthesis of carbonylcontaining acyclic compounds, they clearly indicated the possibility of some applications of nickel species as efficient catalysts in the context of metal-catalyzed carbonylative cyclization involving DMF as a CO surrogate.

In 2015, Ge and co-workers reported the carbonylative cyclization of aromatic $\mathrm{C}\left(\mathrm{sp}^{2}\right)-\mathrm{H}$ and aliphatic $\mathrm{C}\left(\mathrm{sp}^{3}\right)-\mathrm{H}$ bonds of amides 55-57 using DMF as a $\mathrm{CO}$ surrogate, promoted by the synergistic action of $\mathrm{Ni}$ as the main catalyst and $\mathrm{Cu}$ as co-catalyst, to give phthalimides 56 and succinimides 58 as the final products [63]. Concerning the cyclocarbonylation of aromatic amides 55, reactions were carried out with $\mathrm{NiI}_{2}(10 \mathrm{~mol} \%)$ as the main catalyst, $\mathrm{Cu}(\mathrm{acac})_{2}(20 \mathrm{~mol} \%)$ as co-catalyst, $\mathrm{Li}_{2} \mathrm{CO}_{3}$ (0.4 equiv.) as a base, tetraheptylammonium bromide (THAB, 1.0 equiv.) as an additive, in DMF as both reagent and solvent under an $\mathrm{O}_{2}$ atmosphere $(1 \mathrm{~atm})$, at $160^{\circ} \mathrm{C}$ for $24 \mathrm{~h}$ (Scheme 21). Under these conditions, benzamides bearing different functional groups were successfully treated to give the corresponding phthalimide products 56: in particular, substrates with electron-donating substituents (4$\mathrm{MeO}, 4-\mathrm{Me}, 3-\mathrm{MeO}, 2-\mathrm{Me}$ ) afforded the corresponding products in higher yields compared to those bearing electron-withdrawing substituents (4-F, 4- $\mathrm{Cl}, 4-\mathrm{Br}, 4-\mathrm{CN}, 4-\mathrm{CF}_{3}, 4-\mathrm{NO}_{2}$, 3 -Br). Interestingly, reactions took place also with $\alpha$ - and $\beta$-naphthamides, affording the corresponding tricyclic imides in excellent yields, while no reactions occurred with heteroaromatic amides. Carbonylative cyclization of aliphatic amides 57 were instead carried out with $\mathrm{NiBr}_{2}(10 \mathrm{~mol} \%)$ as the main catalyst, $\mathrm{Cu}(\mathrm{acac})_{2}(20 \mathrm{~mol} \%)$ as the cocatalyst, $\mathrm{Na}_{2} \mathrm{CO}_{3}$ (0.3 equiv.) as base, tetrabutylammonium hexafluorophosphate ( $\mathrm{TBAPF}_{6}$, 1.5 equiv.) as additive, in DMF acting as both reagent and solvent, under $\mathrm{O}_{2}$ atmosphere (1 atm), at $160{ }^{\circ} \mathrm{C}$ for $24 \mathrm{~h}$ (Scheme 22). Working with these optimized experimental conditions, 2,2-disubstituted propanamides bearing either linear or cyclic chains were 
successfully converted into the corresponding succinimides 58 in good-to-excellent yields: these results indicated a high site-selectivity in functionalizing the $\beta-\mathrm{C}\left(\mathrm{sp}^{3}\right)-\mathrm{H}$ bond of the methyl group, rather than $\gamma$ - or $\delta-C\left(\mathrm{sp}^{3}\right)-\mathrm{H}$ bonds, showing that the formation of a five-membered ring is favored over the six- or seven-membered rings.

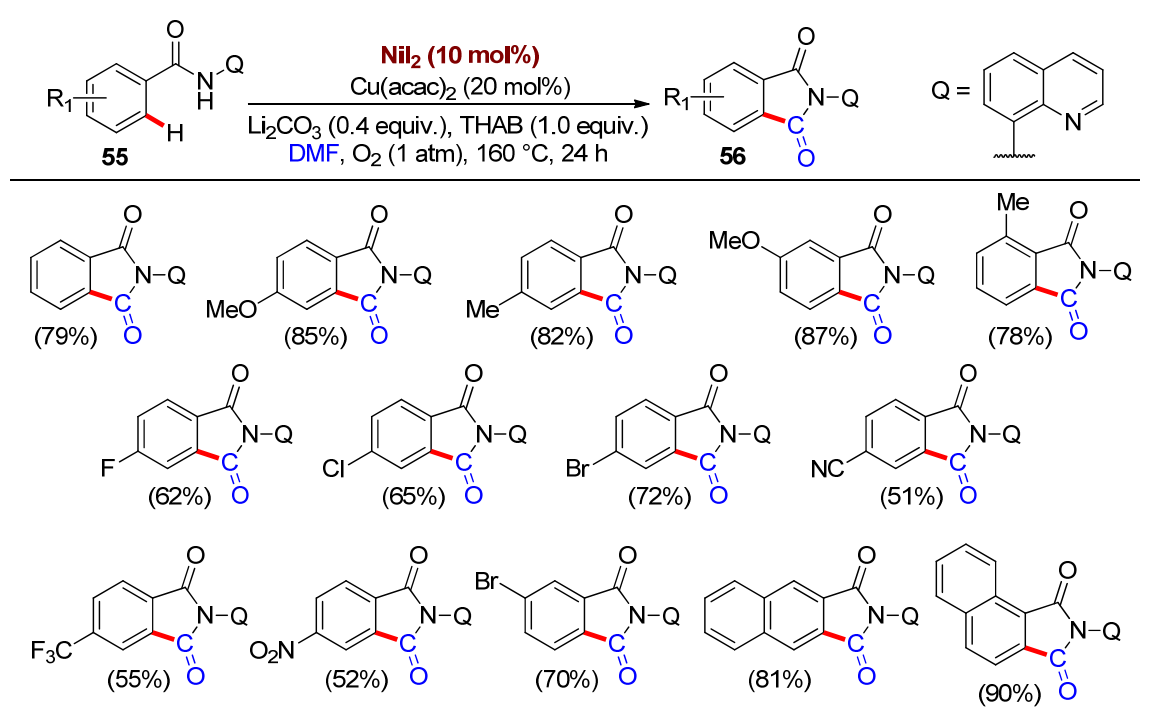

Scheme 21. Synthesis of phthalimides 56 by carbonylative cyclization of aromatic $\mathrm{C}\left(\mathrm{sp}^{2}\right)-\mathrm{H}$ of amides $\mathbf{5 5}$ using DMF as CO surrogate, promoted by the synergistic action of $\mathrm{NiI}_{2}$ as the main catalyst and $\mathrm{Cu}$ (acac) $)_{2}$ as co-catalyst, reported in 2015 by Ge and co-workers [63]. For each heterocyclic carbonylated product, yield after column chromatography purification is reported in brackets.
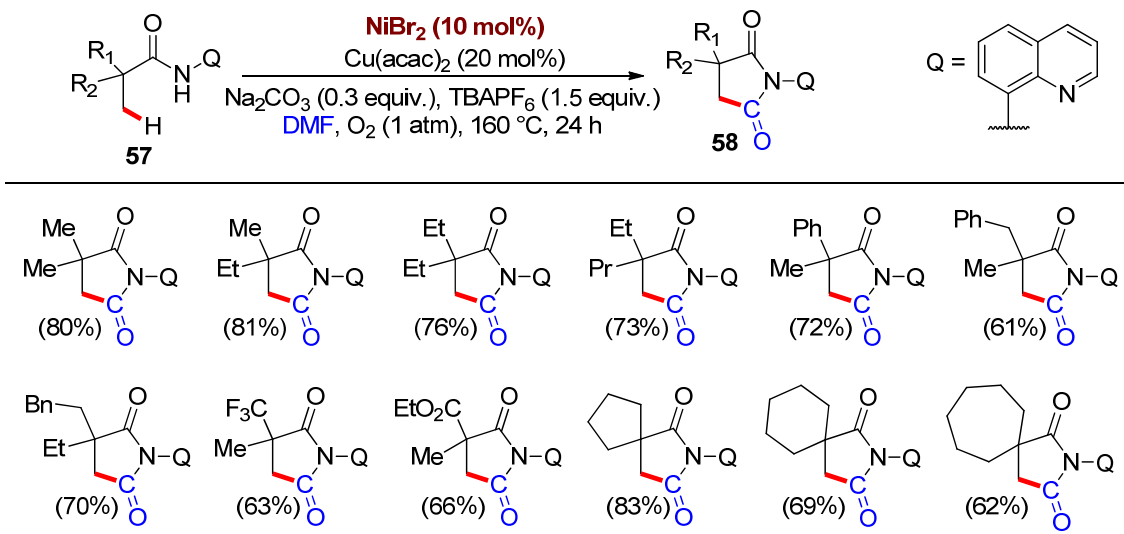

Scheme 22. Synthesis of succinimides 58 by carbonylative cyclization of aliphatic $\mathrm{C}\left(\mathrm{sp}^{3}\right)-\mathrm{H}$ bonds of amides 57 using DMF as a CO surrogate, promoted by the synergistic action of $\mathrm{NiBr}_{2}$ as the main catalyst and $\mathrm{Cu}(\mathrm{acac})_{2}$ as co-catalyst, reported in 2015 by Ge and co-workers [63]. For each heterocyclic carbonylated product, yield after column chromatography purification is reported in brackets.

A very critical point in this work was the determination of the role of DMF, in order to clarify the effective source of carbon monoxide. For this purpose, the authors carried out some control experiments in the cyclocarbonylation of $N$-(quinolin-8-yl)benzamide. On the one hand, by using carbonyl ${ }^{13} \mathrm{C}$ labeled DMF they found only negligible amounts of the corresponding ${ }^{13} \mathrm{C}$ labeled phalimide product; on the other, if working with different $N$-methyl solvents such as $N, N$-dimethylacetamide or $N$-methylpyrrolidone the reaction took place (although in lower yields), no reaction occurred in an $N$-ethyl solvent $(N, N$ diethylformamide). All these results seem to confirm that the methyl group of DMF (rather than the carbonyl group) was involved in the process of carbonylation, similarly to the above-mentioned study of Das and co-workers [58]. 
Ge and co-workers proposed a plausible mechanism for their protocol, which was in agreement with all the experimental evidence, showing the central role of the nickel catalysis in combination with copper acting as a co-catalyst (Scheme 23). First of all, the starting nickel(II) species was coordinated under basic conditions by the nitrogen atom of the amide substrate, affording the nickel(II) complex 59. Then, the $\mathrm{C}-\mathrm{H}$ activation step by the nickel(II) occurred (on the ortho- $\mathrm{C}\left(\mathrm{sp}^{2}\right)-\mathrm{H}$ bond in the case of benzamides and on the $\beta-\mathrm{C}\left(\mathrm{sp}^{3}\right)-\mathrm{H}$ bond in the case of 2,2-disubstituted propanamides), affording the cyclometalated intermediate $\mathbf{6 0}$. Simultaneously, the iminium ion intermediate $\mathbf{6 1}$ was generated in-situ from DMF by a sequential decarbonylation, nucleophilic addition and elimination process promoted by copper(II) species in the presence of $\mathrm{O}_{2}$ as the external oxidant [64-66]. The subsequent nucleophilic addition of 60 to the iminium ion 61 produced the intermediate 62 , which was then oxidized to the iminium salts 63 by the synergistic action of copper(II) and atmospheric $\mathrm{O}_{2}$ as oxidizing agents. The intramolecular nucleophilic addition of the iminium salts 63 afforded the starting nickel(II) species and the intermediate 64 , which was then oxidized and hydrolyzed to yield the final product.

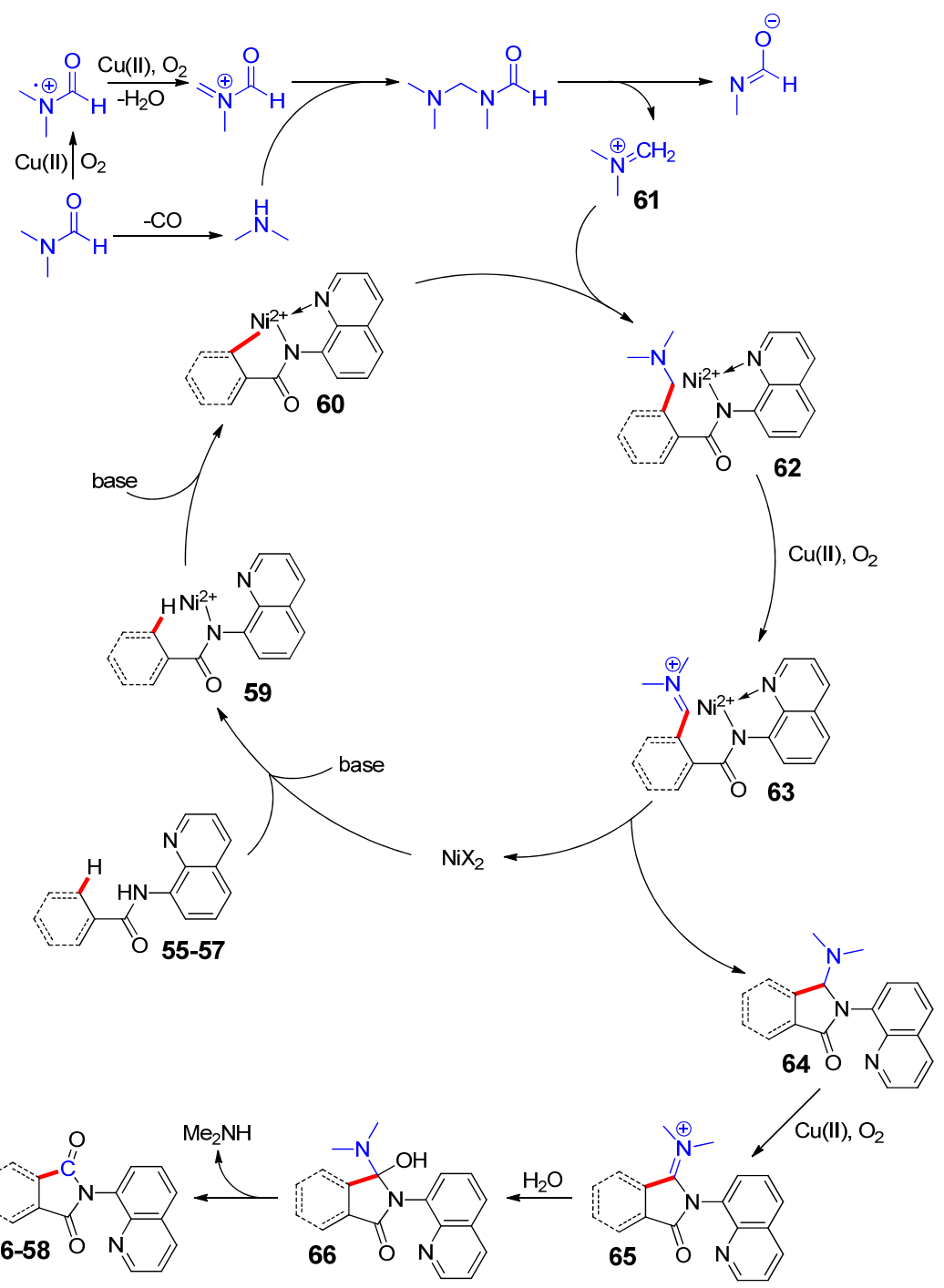

Scheme 23. Proposed reaction mechanism for the synthesis of phthalimides 56 and succinimides 58 by $\mathrm{Ni} / \mathrm{Cu}$ synergistic catalyzed carbonylative cyclization of aromatic $\mathrm{C}\left(\mathrm{sp}^{2}\right)-\mathrm{H}$ and aliphatic $\mathrm{C}\left(\mathrm{sp}^{3}\right)-\mathrm{H}$ bonds of amides 55-57 using DMF as a CO surrogate, reported in 2015 by Ge and coworkers [63]. 
The most important food for thought of this work is represented by the use of nickel as the main catalyst: both $\mathrm{NiBr}_{2}$ and $\mathrm{NiI}_{2}$ are less expensive than $\mathrm{Pd}(\mathrm{OAc})_{2}$ and $\mathrm{Pd} / \mathrm{C}$, and, at the same time, worked through a quite different reaction mechanism. As a consequence, it was possible to apply the DMF-assisted carbonylative cyclization reactions to the synthesis of totally different classes of heterocycles, i.e., phthalimides and succinimides, having well known applications in biological and medicinal chemistry $[67,68]$. Therefore, these results seem to confirm our general impression, that is, the study of alternative metal catalysts could actually extend the types of heterocycles to be synthesized by cyclocarbonylative reactions involving DMF as a $\mathrm{CO}$ surrogate. However, in this context a very important role could also be played by the co-catalyst: in this case $\mathrm{Cu}(\text { acac })_{2}$ (which is also less expensive than AgOTf and all the other silver-based co-catalysts mentioned above) is fundamental in the action mechanism of DMF as a CO surrogate.

It is worth emphasizing that the protocol of Ge and co-workers is not without its drawbacks: working with high catalytic loadings (10-20 mol\%) of homogeneous metal species, at high temperature under conventional thermal heating for a prolonged reaction time, is not very convenient from the point of view of environmental and energy sustainability. However, it represents a very good starting point from which to explore the development of reaction conditions fitting better with the principles of Green Chemistry.

\subsection{Critical Aspects and Perspectives in the Synthesis of Heterocycles by Transition Metal-Catalyzed Carbonylation Reactions Involving DMF as a CO Surrogate}

We believe that a more detailed comparative discussion on critical aspects and perspectives in the application of transition metal-catalyzed carbonylation reactions involving DMF as CO surrogate for the synthesis of heterocycles is mandatory at this stage.

In this class of reactions, a crucial role is played by the transition metal catalyst. Most of them were carried out with a palladium(II) species, typically under ligandless conditions, responsible for a kinetically decisive $\mathrm{C}-\mathrm{H}$ bond activation step from which the catalytic cycle is generated. The use of less expensive nickel(II) species, working through a partially different mechanistic pathway, allowed the extension of the development of cyclocarbonylative protocols to other classes of substrates.

However, the use of a co-catalyst was also crucial, in particular for the involvement of DMF as the carbonyl source in the final heterocyclic products. In the protocols developed by $\mathrm{Wu}$ and co-workers $[41,53]$ carried out in the absence of a metal co-catalyst, the $\mathrm{C}=\mathrm{O}$ functional group of DMF was the effective source of $\mathrm{CO}$ incorporated in the corresponding cyclocarbonylated products; in these cases, the authors hypothesized a thermal- and acid-mediated decomposition of DMF to give $\mathrm{CO}$, which then entered into the catalytic cycle. In the protocols developed by Das et al. [58] and Ge and co-workers [63] performed in the presence of, respectively, a silver and a copper species as co-catalyst, the methyl group of DMF was actually the source of the carbon atom in the carbonyl group of cyclocarbonylated products; the synergystic action of co-catalyst and atmospheric $\mathrm{O}_{2}$ allowed the decomposition of DMF into an iminium species, which then participated to the mechanistic pathway.

As already pointed out in several points of the manuscript, one of the main drawbacks for most of these protocols is the use of homogeneous metal species, often in high metal loading ( $>10 \mathrm{~mol} \%$ ), thus contaminating the final products, which often required long and expensive purification procedures in order to remove metal traces (especially in compounds for agrochemical and medicinal applications). In order to address this issue, a more appealing alternative could be the use of transition metal catalysts supported on solid matrices, which has been investigated to date only in the case of $\mathrm{Wu}$ and co-workers (using commercial Pd/C) [53]. In fact, these catalytic systems (often used with low metal loading) can be easily recovered by simply filtration and then recycled several times, thus reducing the total cost of the process and enabling it to be scaled up to an industrial level. Moreover, their use avoids metal contamination of the desired products, although hot filtration tests and metal leaching analysis are mandatory in order to rule out the occurrence of metal species into the solution. At the same time, the study of new protocols with lower catalytic 
loadings should also be performed: in particular, the determination of typical parameters of catalytic activity such as turnover number (TON) and turnover frequency (TOF) could help in the evaluation and comparison of the efficiency and robustness of each catalyst.

Another very important point that in our opinion needs to be further explored is the possibility to apply carbonylative cyclization involving DMF as a CO source to the synthesis of other classes of heterocycles. In this context, we are confident that the use of other metal species as the main catalyst and/or co-catalyst could represent an important opportunity for new advances. It is worth emphasizing that, in some cases, heterogeneous catalysis allows the achievement a specific chemo- and regioselectivity, which is different with respect to the corresponding homogeneous processes. Therefore, the study of supported catalysts in this class of reactions would be highly desirable not only because they allow for an easy separation from reaction medium, but also for the development of new advantageous synthetic protocols for the synthesis of different heterocycles, including for potential applications in supramolecular and material chemistry.

\section{Conclusions}

In this mini-review we provided, for the first time, a critical account of the emergent application of DMF as a CO source in transition metal-catalyzed carbonylation reactions, giving, on the one hand, a general state of the art of these reactions for the preparation of carbonyl- containing molecules, and, on the other, a more detailed discussion of their application in the synthesis of heterocycles. The use of DMF has certainly offered several advantages in the context of metal-catalyzed carbonylation: due to the difficulty in the handling, storage and transport of carbon monoxide, which is a highly flammable and toxic greenhouse gas requiring high- pressure equipment (an autoclave or, at least, two-chamber systems), DMF is recently finding success as a CO surrogate because it is cheap and easily accessible, easy to manipulate and also scalable. Although the examples described in the literature may appear still quite limited, our concise and critical overview was very useful in emphasizing and comparing both advantages and drawbacks, suggesting perspectives on developments, trends and future directions in the context of metal-catalyzed carbonylative protocols, and in particular for the synthesis of heterocycles.

In conclusion, we believe that our mini-review could really help the broad community of synthetic organic chemists in the development of new high-yielding and selective methods for the production of carbonyl-containing compounds, and in particular heterocyclic compounds, by transition metal-catalyzed carbonylative reactions involving the use of DMF as a CO surrogate, offering important food for thought for the near future.

Author Contributions: Conceptualization, B.P.; data curation, B.P. and G.A.; writing-original draft preparation, B.P. and G.A.; writing-review and editing, G.A.; supervision, G.A. All authors have read and agreed to the published version of the manuscript.

Funding: This research received no external funding.

Data Availability Statement: Not applicable.

Acknowledgments: B.P. is thankful to City College, Kolkata-700009 for their kind support. B.P. is also grateful to all the faculty members of the Department of Chemistry, City College, Kolkata, for their ongoing assistance and encouragement. B.P. expresses gratitude to Bhaskar Paul, Aranya Sarkar, Totan Mondal and Sujay Nandi for their unwavering help.

Conflicts of Interest: The authors declare no conflict of interest.

\section{References}

1. Semchyshyn, H.M. Reactive Carbonyl Species In Vivo: Generation and Dual Biological Effects. Sci. World J. 2014, $2014,417842$. [CrossRef]

2. Li, M.; Zajaczkowski, W.; Velpula, G.; Jänsch, D.; Graf, R.; Marszalek, T.; Parekh, S.H.; Zagranyarski, Y.; Mali, K.; Wagner, M.; et al. Transformation from helical to layered supramolecular organization of asymmetric perylene diimides via multiple intermolecular hydrogen bonding. Chem. Sci. 2020, 11, 4960-4968. [CrossRef] 
3. Hassan Omar, O.; Falcone, M.; Operamolla, A.; Albano, G. Impact of chirality on the aggregation modes of L-phenylalanine- and D-glucose-decorated phenylene-thiophene oligomers. New J. Chem. 2021, 45, 12016-12023. [CrossRef]

4. Schoenberg, A.; Bartoletti, I.; Heck, R.F. Palladium-catalyzed carboalkoxylation of aryl, benzyl, and vinylic halides. J. Org. Chem. 1974, 39, 3318-3326. [CrossRef]

5. Wu, X.-F.; Neumann, H.; Beller, M. Palladium-catalyzed carbonylative coupling reactions between Ar-X and carbon nucleophiles. Chem. Soc. Rev. 2011, 40, 4986-5009. [CrossRef] [PubMed]

6. Peng, J.-B.; Qi, X.; Wu, X.-F. Recent Achievements in Carbonylation Reactions: A Personal Account. Synlett 2017, $28,175-194$.

7. Dekleva, T.W.; Forster, D. The rhodium-catalyzed carbonylation of linear primary alcohols. J. Am. Chem. Soc. 1985, 107, 3565-3567. [CrossRef]

8. Haynes, A.; Maitlis, P.M.; Morris, G.E.; Sunley, G.J.; Adams, H.; Badger, P.W.; Bowers, C.M.; Cook, D.B.; Elliott, P.I.P.; Ghaffar, T.; et al. Promotion of Iridium-Catalyzed Methanol Carbonylation: Mechanistic Studies of the Cativa Process. J. Am. Chem. Soc. 2004, 126, 2847-2861. [CrossRef]

9. Morimoto, T.; Kakiuchi, K. Evolution of Carbonylation Catalysis: No Need for Carbon Monoxide. Angew. Chem. Int. Ed. 2004, 43, 5580-5588. [CrossRef]

10. Wu, L.; Liu, Q.; Jackstell, R.; Beller, M. Carbonylations of Alkenes with CO Surrogates. Angew. Chem. Int. Ed. 2014, 53, 6310-6320. [CrossRef]

11. Gautam, P.; Bhanage, B.M. Recent advances in the transition metal catalyzed carbonylation of alkynes, arenes and aryl halides using CO surrogates. Catal. Sci. Technol. 2015, 5, 4663-4702. [CrossRef]

12. Chen, J.; Natte, K.; Spannenberg, A.; Neumann, H.; Beller, M.; Wu, X.-F. Palladium-Catalyzed Carbonylative [3+2+1] Annulation of N-Aryl-Pyridine-2-Amines with Internal Alkynes by C-H Activation: Facile Synthesis of 2-Quinolinones. Chem. Eur. J. 2014, 20, 14189-14193. [CrossRef]

13. Cao, J.; Zheng, Z.-J.; Xu, Z.; Xu, L.-W. Transition-metal-catalyzed transfer carbonylation with HCOOH or HCHO as non-gaseous C1 source. Coord. Chem. Rev. 2017, 336, 43-53. [CrossRef]

14. Li, H.; Neumann, H.; Beller, M.; Wu, X.-F. Aryl Formate as Bifunctional Reagent: Applications in Palladium-Catalyzed Carbonylative Coupling Reactions Using In Situ Generated CO. Angew. Chem. Int. Ed. 2014, 53, 3183-3186. [CrossRef] [PubMed]

15. Natte, K.; Dumrath, A.; Neumann, H.; Beller, M. Palladium-Catalyzed Carbonylations of Aryl Bromides using Paraformaldehyde: Synthesis of Aldehydes and Esters. Angew. Chem. Int. Ed. 2014, 53, 10090-10094. [CrossRef] [PubMed]

16. Shil, A.K.; Kumar, S.; Reddy, C.B.; Dadhwal, S.; Thakur, V.; Das, P. Supported Palladium Nanoparticle-Catalyzed Carboxylation of Aryl Halides, Alkenylsilanes, and Organoboronic Acids Employing Oxalic Acid as the C1 Source. Org. Lett. 2015, 17, 5352-5355. [CrossRef]

17. Lescot, C.; Nielsen, D.U.; Makarov, I.S.; Lindhardt, A.T.; Daasbjerg, K.; Skrydstrup, T. Efficient Fluoride-Catalyzed Conversion of CO2 to CO at Room Temperature. J. Am. Chem. Soc. 2014, 136, 6142-6147. [CrossRef]

18. Mondal, K.; Halder, P.; Gopalan, G.; Sasikumar, P.; Radhakrishnan, K.V.; Das, P. Chloroform as a CO surrogate: Applications and recent developments. Org. Biomol. Chem. 2019, 17, 5212-5222. [CrossRef]

19. Albano, G.; Aronica, L.A. Potentiality and Synthesis of O- and N-Heterocycles: Pd-Catalyzed Cyclocarbonylative Sonogashira Coupling as a Valuable Route to Phthalans, Isochromans, and Isoindolines. Eur. J. Org. Chem. 2017, 2017, 7204-7221. [CrossRef]

20. Aronica, L.A.; Albano, G.; Giannotti, L.; Meucci, E. Synthesis of N-Heteroaromatic Compounds through Cyclocarbonylative Sonogashira Reactions. Eur. J. Org. Chem. 2017, 2017, 955-963. [CrossRef]

21. Albano, G.; Giuntini, S.; Aronica, L.A. Synthesis of 3-Alkylideneisoindolin-1-ones via Sonogashira Cyclocarbonylative Reactions of 2-Ethynylbenzamides. J. Org. Chem. 2020, 85, 10022-10034. [CrossRef]

22. Albano, G.; Evangelisti, C.; Aronica, L.A. Palladium Nanoparticles Supported on Smopex-234 ${ }^{\circledR}$ as Valuable Catalysts for the Synthesis of Heterocycles. Catalysts 2021, 11, 706. [CrossRef]

23. Albano, G.; Morelli, M.; Aronica, L.A. Synthesis of Functionalised 3-Isochromanones by Silylcarbocyclisation/Desilylation Reactions. Eur. J. Org. Chem. 2017, 2017, 3473-3480. [CrossRef]

24. Albano, G.; Morelli, M.; Lissia, M.; Aronica, L.A. Synthesis of Functionalised Indoline and Isoquinoline Derivatives through a Silylcarbocyclisation/Desilylation Sequence. ChemistrySelect 2019, 4, 2505-2511. [CrossRef]

25. Albano, G.; Aronica, L.A. From Alkynes to Heterocycles through Metal-Promoted Silylformylation and Silylcarbocyclization Reactions. Catalysts 2020, 10, 1012. [CrossRef]

26. Chen, Z.; Wang, L.-C.; Wu, X.-F. Carbonylative synthesis of heterocycles involving diverse CO surrogates. Chem. Commun. 2020, 56, 6016-6030. [CrossRef]

27. Ding, S.; Jiao, N. N,N-Dimethylformamide: A Multipurpose Building Block. Angew. Chem. Int. Ed. 2012, 51, 9226-9237. [CrossRef]

28. Wan, Y.; Alterman, M.; Larhed, M.; Hallberg, A. Dimethylformamide as a Carbon Monoxide Source in Fast Palladium-Catalyzed Aminocarbonylations of Aryl Bromides. J. Org. Chem. 2002, 67, 6232-6235. [CrossRef]

29. Heravi, M.M.; Ghavidel, M.; Mohammadkhani, L. Beyond a solvent: Triple roles of dimethylformamide in organic chemistry. RSC Adv. 2018, 8, 27832-27862. [CrossRef]

30. Hosoi, K.; Nozaki, K.; Hiyama, T. Carbon Monoxide Free Aminocarbonylation of Aryl and Alkenyl Iodides Using DMF as an Amide Source. Org. Lett. 2002, 4, 2849-2851. [CrossRef]

31. Vilsmeier, A.; Haack, A. Über die Einwirkung von Halogenphosphor auf Alkyl-formanilide. Eine neue Methode zur Darstellung sekundärer und tertiärer p-Alkylamino-benzaldehyde. Ber. Dtsch. Chem. Ges. 1927, 60, 119-122. [CrossRef] 
32. Tambade, P.J.; Patil, Y.P.; Bhanushali, M.J.; Bhanage, B.M. Pd/C: An efficient, heterogeneous and reusable catalyst for carbon monoxide-free aminocarbonylation of aryl iodides. Tetrahedron Lett. 2008, 49, 2221-2224. [CrossRef]

33. Sawant, D.N.; Wagh, Y.S.; Bhatte, K.D.; Bhanage, B.M. Palladium-Catalyzed Carbon-Monoxide-Free Aminocarbonylation of Aryl Halides Using N-Substituted Formamides as an Amide Source. J. Org. Chem. 2011, 76, 5489-5494. [CrossRef]

34. Feng, X.; Li, Z. Photocatalytic promoting dimethylformamide (DMF) decomposition to in-situ generation of self-supplied CO for carbonylative Suzuki reaction. J. Photochem. Photobiol. A 2017, 337, 19-24. [CrossRef]

35. Tasker, S.Z.; Standley, E.A.; Jamison, T.F. Recent advances in homogeneous nickel catalysis. Nature 2014, 509, 299-309. [CrossRef]

36. Cooper, A.K.; Burton, P.M.; Nelson, D.J. Nickel versus Palladium in Cross-Coupling Catalysis: On the Role of Substrate Coordination to Zerovalent Metal Complexes. Synthesis 2020, 52, 565-573. [CrossRef]

37. Ju, J.; Jeong, M.; Moon, J.; Jung, H.M.; Lee, S. Aminocarbonylation of Aryl Halides Using a Nickel Phosphite Catalytic System. Org. Lett. 2007, 9, 4615-4618. [CrossRef] [PubMed]

38. Jo, Y.; Ju, J.; Choe, J.; Song, K.H.; Lee, S. The Scope and Limitation of Nickel-Catalyzed Aminocarbonylation of Aryl Bromides from Formamide Derivatives. J. Org. Chem. 2009, 74, 6358-6361. [CrossRef]

39. Li, Y.; Tu, D.-H.; Wang, B.; Lu, J.-Y.; Wang, Y.-Y.; Liu, Z.-T.; Liu, Z.-W.; Lu, J. Nickel-catalyzed carbonylation of arylboronic acids with DMF as a CO source. Org. Chem. Front. 2017, 4, 569-572. [CrossRef]

40. Feng, Y.; Zhang, K.; Yan, B.; Li, S.; Du, Y. Hydrothermal Method Using DMF as a Reducing Agent for the Fabrication of PdAg Nanochain Catalysts towards Ethanol Electrooxidation. Catalysts 2016, 6, 103. [CrossRef]

41. Chen, J.; Feng, J.-B.; Natte, K.; Wu, X.-F. Palladium-Catalyzed Carbonylative Cyclization of Arenes by C-H Bond Activation with DMF as the Carbonyl Source. Chem. Eur. J. 2015, 21, 16370-16373. [CrossRef]

42. Chen, J.; Natte, K.; Spannenberg, A.; Neumann, H.; Langer, P.; Beller, M.; Wu, X.-F. Base-Controlled Selectivity in the Synthesis of Linear and Angular Fused Quinazolinones by a Palladium-Catalyzed Carbonylation/Nucleophilic Aromatic Substitution Sequence. Angew. Chem. Int. Ed. 2014, 53, 7579-7583. [CrossRef]

43. Khan, I.; Ibrar, A.; Abbas, N.; Saeed, A. Recent advances in the structural library of functionalized quinazoline and quinazolinone scaffolds: Synthetic approaches and multifarious applications. Eur. J. Med. Chem. 2014, 76, 193-244. [CrossRef] [PubMed]

44. Khan, I.; Zaib, S.; Batool, S.; Abbas, N.; Ashraf, Z.; Iqbal, J.; Saeed, A. Quinazolines and quinazolinones as ubiquitous structural fragments in medicinal chemistry: An update on the development of synthetic methods and pharmacological diversification. Biorg. Med. Chem. 2016, 24, 2361-2381. [CrossRef] [PubMed]

45. Horváth, I.T.; Anastas, P.T. Innovations and Green Chemistry. Chem. Rev. 2007, 107, 2169-2173. [CrossRef] [PubMed]

46. Anastas, P.; Eghbali, N. Green Chemistry: Principles and Practice. Chem. Soc. Rev. 2010, 39, 301-312. [CrossRef] [PubMed]

47. Panda, B.; Sarkar, T.K. Gold and Palladium Combined for the Sonogashira Coupling of Aryl and Heteroaryl Halides. Synthesis 2013, 45, 817-829.

48. Mphahlele, M.J.; Maluleka, M.M. Advances in Metal-Catalyzed Cross-Coupling Reactions of Halogenated Quinazolinones and Their Quinazoline Derivatives. Molecules 2014, 19, 17435-17463. [CrossRef] [PubMed]

49. Campanati, M.; Fornasari, G.; Vaccari, A. Fundamentals in the preparation of heterogeneous catalysts. Catal. Today 2003, 77, 299-314. [CrossRef]

50. Copéret, C.; Chabanas, M.; Petroff Saint-Arroman, R.; Basset, J.-M. Homogeneous and Heterogeneous Catalysis: Bridging the Gap through Surface Organometallic Chemistry. Angew. Chem. Int. Ed. 2003, 42, 156-181. [CrossRef] [PubMed]

51. Astruc, D.; Lu, F.; Aranzaes, J.R. Nanoparticles as Recyclable Catalysts: The Frontier between Homogeneous and Heterogeneous Catalysis. Angew. Chem. Int. Ed. 2005, 44, 7852-7872. [CrossRef]

52. Albano, G.; Evangelisti, C.; Aronica, L.A. Hydrogenolysis of Benzyl Protected Phenols and Aniline Promoted by Supported Palladium Nanoparticles. ChemistrySelect 2017, 2, 384-388. [CrossRef]

53. Chen, J.; Natte, K.; Wu, X.-F. Pd/C-catalyzed carbonylative C-H activation with DMF as the CO source. Tetrahedron Lett. 2015, 56, 6413-6416. [CrossRef]

54. Bhattacharya, T.; Dutta, S.; Maiti, D. Deciphering the Role of Silver in Palladium-Catalyzed C-H Functionalizations. ACS Catal. 2021, 11, 9702-9714. [CrossRef]

55. Piou, T.; Slutskyy, Y.; Kevin, N.J.; Sun, Z.; Xiao, D.; Kong, J. Direct Arylation of Azoles Enabled by Pd/Cu Dual Catalysis. Org. Lett. 2021, 23, 1996-2001. [CrossRef]

56. Hamlin, J.E.; Hirai, K.; Millan, A.; Maitlis, P.M. A Simple Practical Test for Distinguishing a Heterogeneous Component in an Homogeneously Catalysed Reaction. J. Mol. Catal. A Chem. 1980, 7, 543-544.

57. Albano, G.; Interlandi, S.; Evangelisti, C.; Aronica, L.A. Polyvinylpyridine-Supported Palladium Nanoparticles: A Valuable Catalyst for the Synthesis of Alkynyl Ketones via Acyl Sonogashira Reactions. Catal. Lett. 2020, 150, 652-659. [CrossRef]

58. Nageswar Rao, D.; Rasheed, S.; Das, P. Palladium/Silver Synergistic Catalysis in Direct Aerobic Carbonylation of C(sp $\left.{ }^{2}\right)-\mathrm{H}$ Bonds Using DMF as a Carbon Source: Synthesis of Pyrido-Fused Quinazolinones and Phenanthridinones. Org. Lett. 2016, 18, 3142-3145. [CrossRef]

59. Aleti, R.R.; Festa, A.A.; Voskressensky, L.G.; Van der Eycken, E.V. Synthetic Strategies in the Preparation of Phenanthridinones. Molecules 2021, 26, 5560. [CrossRef]

60. Nakamura, M.; Aoyama, A.; Salim, M.T.A.; Okamoto, M.; Baba, M.; Miyachi, H.; Hashimoto, Y.; Aoyama, H. Structural development studies of anti-hepatitis C virus agents with a phenanthridinone skeleton. Biorg. Med. Chem. 2010, 18, $2402-2411$. [CrossRef] 
61. Fang, Y.; Tranmer, G.K. Continuous flow photochemistry as an enabling synthetic technology: Synthesis of substituted-6(5H)phenanthridinones for use as poly(ADP-ribose) polymerase inhibitors. MedChemComm 2016, 7, 720-724. [CrossRef]

62. Nishiyama, Y.; Mori, S.; Makishima, M.; Fujii, S.; Kagechika, H.; Hashimoto, Y.; Ishikawa, M. Novel Nonsteroidal Progesterone Receptor (PR) Antagonists with a Phenanthridinone Skeleton. ACS Med. Chem. Lett. 2018, 9, 641-645. [CrossRef] [PubMed]

63. Wu, X.; Zhao, Y.; Ge, H. Direct Aerobic Carbonylation of $\mathrm{C}\left(\mathrm{sp}^{2}\right)-\mathrm{H}$ and $\mathrm{C}\left(\mathrm{sp}^{3}\right)-\mathrm{H}$ Bonds through Ni/Cu Synergistic Catalysis with DMF as the Carbonyl Source. J. Am. Chem. Soc. 2015, 137, 4924-4927. [CrossRef] [PubMed]

64. Lao, Z.-Q.; Zhong, W.-H.; Lou, Q.-H.; Li, Z.-J.; Meng, X.-B. KI-catalyzed imidation of sp ${ }^{3}$ C-H bond adjacent to amide nitrogen atom. Org. Biomol. Chem. 2012, 10, 7869-7871. [CrossRef]

65. Itoh, M.; Hirano, K.; Satoh, T.; Miura, M. Copper-Catalyzed $\alpha$-Methylenation of Benzylpyridines Using Dimethylacetamide as One-Carbon Source. Org. Lett. 2014, 16, 2050-2053. [CrossRef]

66. Li, Y.; Xue, D.; Lu, W.; Wang, C.; Liu, Z.-T.; Xiao, J. DMF as Carbon Source: Rh-Catalyzed $\alpha$-Methylation of Ketones. Org. Lett. 2014, 16, 66-69. [CrossRef]

67. Kushwaha, N.; Kaushik, D. Recent Advances and Future Prospects of Phthalimide Derivatives. J. App. Pharm. Sci. 2016, 6, 159-171. [CrossRef]

68. Zhao, Z.; Yue, J.; Ji, X.; Nian, M.; Kang, K.; Qiao, H.; Zheng, X. Research progress in biological activities of succinimide derivatives. Bioorg. Chem. 2021, 108, 104557. [CrossRef] 